\title{
$A \beta$ accumulation causes MVB enlargement and is modelled by dominant negative VPS4A
}

\author{
Katarina Willén ${ }^{1}$, James R. Edgarr ${ }^{2,3}$, Takafumi Hasegawa ${ }^{4}$, Nobuyuki Tanaka ${ }^{5}$, Clare E. Futter ${ }^{3}$ and Gunnar K. Gouras ${ }^{1 *}$
}

\begin{abstract}
Background: Alzheimer's disease (AD)-linked $\beta$-amyloid (Aß) accumulates in multivesicular bodies (MVBs) with the onset of $A D$ pathogenesis. Alterations in endosomes are among the earliest changes associated with $A D$ but the mechanism(s) that cause endosome enlargement and the effects of MVB dysfunction on A $\beta$ accumulation and tau pathology are incompletely understood.

Methods: MVB size and A $\beta$ fibrils in primary neurons were visualized by electron microscopy and confocal fluorescent microscopy. MVB-dysfunction, modelled by expression of dominant negative VPS4A (dnVPS4A), was analysed by biochemical methods and exosome isolation.

Results: Here we show that AD transgenic neurons have enlarged MVBs compared to wild type neurons. Uptake of exogenous $A \beta$ also leads to enlarged MVBs in wild type neurons and generates fibril-like structures in endocytic vesicles. With time fibrillar oligomers/fibrils can extend out of the endocytic vesicles and are eventually detectable extracellularly. Further, endosomal sorting complexes required for transport (ESCRT) components were found associated with amyloid plaques in AD transgenic mice. The phenotypes previously reported in $A D$ transgenic neurons, with net increased intracellular levels and reduced secretion of $A \beta$, were mimicked by blocking recycling of ESCRT-III by dnVPS4A. DnVPS4A further resembled AD pathology by increasing tau phosphorylation at serine 396 and increasing markers of autophagy.

Conclusions: We demonstrate that A $\beta$ leads to MVB enlargement and that amyloid fibres can form within the endocytic pathway of neurons. These results are consistent with the scenario of the endosome-lysosome system representing the site of initiation of $A \beta$ aggregation. In turn, a dominant negative form of the CHMP2B-interacting protein VPS4A, which alters MVBs, leads to accumulation and aggregation of A $\beta$ as well as tau phosphorylation, mimicking the cellular changes in AD.
\end{abstract}

Keywords: Alzheimer's disease, Amyloid, Endocytosis, Multivesicular body, Tau

\section{Background}

Alzheimer's disease $(\mathrm{AD})$ is characterized by progressive decline in cognitive function, anatomical selective loss of synapses and neurons, and aggregation of the $\beta$-amyloid peptide $(A \beta)$ in amyloid plaques and hyperphosphorylated tau in neurofibrillary tangles (NFTs). Although plaques are extracellular aggregates of $A \beta$, accumulation of $A \beta 42$, the most pathogenic $A \beta$ peptide, begins within neurons in

\footnotetext{
*Correspondence: gunnar.gouras@med.lu.se

'Department of Experimental Medical Science, Lund University, 22184 Lund, Sweden

Full list of author information is available at the end of the article
}

$\mathrm{AD}[1-3]$ and in $\mathrm{AD}$ transgenic mouse models [4-6]. In $\mathrm{AD}$ transgenic mice, cognitive, physiological and structural impairments appear prior to plaques [7-9] and are accompanied by intraneuronal $A \beta$ peptide accumulation, supporting that accumulation of intraneuronal $A \beta$ peptides is one of the earliest events in AD pathogenesis [10].

Abnormalities in the endocytic pathway are also among the earliest pathological features reported in $\mathrm{AD}$, preceding the classical pathological markers of $A \beta$ plaques and NFTs [11]. Specifically, enlargement of Rab5-positive early endosomes and Rab7-positive late endosomes were reported in $\mathrm{AD}[12,13]$, as well as progressive accumulation 
of multivesicular bodies (MVBs), lysosomes and autophagic vacuoles [14]. The amyloidogenic cleavage of APP occurs predominantly in endosomes [15-19]. Proteins in the amyloidogenic pathway (APP, the $\beta$-site APP cleaving enzyme (BACE1) and the $\gamma$-secretase that generates the $A \beta$ peptides) are transmembrane proteins that traffic through the secretory pathway as well as the endocytic pathway. Immuno-electron microscopy revealed that particularly the limiting membrane of MVBs are the normal location of $A \beta 42$ in neurons of the brain and are the sites of $A \beta$ accumulation during AD pathogenesis [20], especially at synapses [5]. Sorting of EGFR via the MVB pathway was impaired by endosomal $A \beta$ accumulation in cultured $A D$ transgenic neurons [21]. Translocation into MVBs appeared particularly affected, suggesting $A \beta$ dependent dysfunction of the late endosomal sorting complexes required for transport (ESCRT) pathway in AD.

The ESCRTs are a set of proteins conserved from yeast to mammals that regulate and drive formation of the intraluminal vesicles of MVBs. They assemble into distinct subcomplexes: ESCRT-0, ESCRT-I, ESCRT-II and ESCRT-III. Their sequential action directs the sorting of ubiquitinated transmembrane proteins and the inward budding of intraluminal vesicles (ILVs) into the lumen of endosomes, thereby generating MVBs that then either deliver membrane-associated cargo to the lysosome for degradation, release the intraluminal vesicles (then called exosomes) via fusion with the plasma membrane or traffic cargo back to the Golgi apparatus. ESCRT-III subunits, among them CHMP2B, are inactive monomers in the cytoplasm [22] that assemble on endosomal membranes in an ordered manner to generate the transient ESCRT-III complex. CHMP2B, linked genetically to frontotemporal dementia (FTD) and AD [23, 24], directly interacts with and recruits the VPS4 AAA-ATPase complex that disassembles ESCRT-III, and genome-wide association studies for late onset AD identified an association with VPS4B [25].

Given the cumulative genetic, biological and pathological evidence implicating $A \beta$ in $A D$, and the early accumulation of $A \beta$ in MVBs in $A D$, we set out to test our first hypothesis (1) that $A \beta$ can cause the abnormal endosomal phenotype seen in $\mathrm{AD}$. To determine this, we investigated the effects of $A \beta$ on MVB size and $A \beta$ aggregation in late endosomes. Since $A \beta$ accumulates particularly at the outer limiting membrane of MVBs where ESCRTs reside and since ESCRT dysfunction leads to endosomal enlargement we also tested our second hypothesis (2) that $A \beta$ causes dysfunction of the ESCRT pathway. This was investigated by examining changes in ESCRT proteins in primary neurons, as well as modulating the late ESCRT pathway to examine how this influences $A \beta$ accumulation.

Here we provide experimental evidence of $A \beta$-dependent MVB enlargement as well as $A \beta$ aggregation within late endocytic compartments of neurons. Consistent with the scenario of MVBs representing the site of initiation of $A \beta$ aggregation, the accumulation of neuronal ESCRT components was evident in amyloid plaques. Moreover, dysfunction of ESCRT-III, modelled by dominant negative VPS4A (dnVPS4A) mimicked the $A \beta$ accumulation and aggregation in MVBs as well as the enlarged late endosomal size seen in $\mathrm{AD}$. These results support a novel scenario where a vicious cycle of ESCRT-dependent late endosomal dysfunction causes further $A \beta$ accumulation as well as $A D$ pathogenic tau phosphorylation.

\section{Methods \\ Cell culture}

Primary neuronal cultures were generated from B6.Cg- $\mathrm{Tg}$ (APPswe, PSEN1dE9)85Dbo/Mmjax mice (APP/PS1) AD transgenic ( $\mathrm{tg}$ ) and wild-type (wt) mouse embryos. The APP sequence in APP/PS1 encodes a chimeric mouse/human APP (Mo/HuAPP695swe) that was humanized by modifying three amino acids, and introducing the Swedish AD mutation. The PS1 sequence encodes human presenilin 1 lacking exon 9 (dE9) that models AD-associated mutations in PS1. Both APPswe and PS1 are independently controlled by the prion protein promoter. Primary neuronal cultures were prepared from cortices and hippocampi of embryonic day 15 embryos as previously described [9]. In brief, E15 brain tissue was dissociated by trypsinization and trituration in DMEM with 10\% fetal bovine serum (Gibco). Dissociated neurons were cultured on poly-D-lysine (Sigma) coated plates or glass coverslips (Bellco Glass Inc.) and were maintained until 12 and 19 DIV in neurobasal medium (Gibco), B27 supplement (Gibco), glutamine (Invitrogen) and antibiotics (ThermoScientific).

Wild type mouse N2a neuroblastoma cells (N2a) or N2a cells stably transfected with the 670/671 Swedish mutation human APP (Swe) [26] or wild-type $\alpha$-synuclein with HATag ( $\alpha$-syn) were grown on $10 \mathrm{~cm}$ dishes or coverslips.

\section{Electron microscopy}

Cells were grown on Thermanox coverslips (Nalgene, Nunc) and fixed with 2\% PFA, 2.5\% glutaraldehyde in $0.1 \mathrm{M}$ cacodylate. Cells were then secondarily fixed with $1 \%$ osmium tetroxide followed by incubation with $1 \%$ tannic acid to enhance contrast. Cells were dehydrated using increasing percentages of ethanol before being embedded onto Epoxy resin (Agar scientific, UK) stubs. Coverslips were cured overnight at $65{ }^{\circ} \mathrm{C}$. Ultrathin sections were cut using a diamond knife mounted to a Reichert ultracut $\mathrm{S}$ ultramicrotome and sections were collected onto copper grids. Grids were post-stained with drops of lead citrate. Sections were viewed on a FEI Tecnai transmission electron microscope (Eindhoven, The Netherlands) at a working voltage of $80 \mathrm{kV}$. BSA-gold was prepared as previously described [27]. For quantification of MVB diameter, MVBs 
were defined as organelles containing intraluminal vesicles and monomeric rather than flocculated BSA-gold.

A $31-42$ peptides (Sigma) were incubated at $37{ }^{\circ} \mathrm{C}$ for $1 \mathrm{~h}$ to induce fibril formation in vitro. Grids were inverted onto the drops of $\mathrm{A} \beta 1-42$, negatively stained with $2 \%$ uranyl acetate, washed with water and dried on filter paper before being viewed by EM.

\section{Transfection and constructs}

Cells were transfected using Lipofectamine 2000 (Invitrogen) for N2a cells or Lipofectamine 3000 (Invitrogen) for primary neurons. N2a cells were transfected in Opti-MEM while primary neurons were transfected directly in their growth medium. The plasmids p3xFLAG-CMV-10hVPS4A-wt and p3xFLAG-CMV-10-hVPS4A-dn E228Q were generated as described [28]. The control plasmids p3xFLAG-CMV-7-BAP Control Plasmid was purchased from Sigma-Aldrich and pcDNA3-CMV-GFP from Addgene. pcDNA3-synapsin-FLAG-wtVPS4 and pcDNA3synapsin-FLAG-dnVPS4 were constructed from pcDNA3synapsin-FLAG and PCR products from the p3xFLAGCMV-10-hVPS4A-wt and p3xFLAG-CMV-10-hVPS4A-dn respectively. Control plasmid pAAV-synapsin-GFP was purchased from Addgene.

\section{Antibodies and reagents}

The following antibodies were used (see also Additional file 1: Table S1): 369 [29] (Buxbaum et al., 1990) for Western blot (WB) 1:1000; 6E10 (BioLegend, previously Covance SIG-39320) IF: 1:500, WB 1:1000; 12F4 (BioLegend, previously Covance SIG-39142) for immunofluorescence (IF) 1:250; Amyloid $\beta$ (1-42) (IBL, 18,582); Amyloid 3 (1-42) (Invitrogen, 700,254) IF 1:1000; beta-actin (Sigma, A 5316) WB 1:2000; CD63 (ThermoFisher Scientific, MAI-19281) WB 1:1000; CHMP2B (Abcam, ab33174) IF 1:250, WB 1:1000; Clavestin-1 + 2 (Bioss, bs-6569R-A647) IF 1:250; DAPI (Sigma, D9542) IF 1:2000; drebrin (Abcam, ab11068) IF 1:1000; FLAG (Biolegend, 637,302) IF 1:1000, (Sigma, F1804) WB 1:1000; Flotillin-1 (BD Biosciences, 610,821) IF 1:400; GM130 (BD Biosciences, 610,822) IF: 1:500; GSK3 $\beta$ (Cell Signaling Technology, 12,456) IF 1:400; pGSK $\alpha / \beta$ (Cell Signaling Technology, 9331S) WB 1:1000; HA-Tag (Cell Signaling Technology, 3724) WB 1:1000; Hrs and Hrs-2 (Enzo, ALX-804-382-C050) IF 1:100; LAMP1 (Abcam, ab24170) IF 1:1000; LAMP1 (Abcam, ab25245) IF: 1:1500; LC3 $\beta$ (Cell Signaling Technology, 2775) WB 1:1000; Amyloid fibrils OC (Merck Millipore, AB2286) IF 1:1000; P2:1 (ThermoFisher Scientific, OMA1-03132) IF 1:500; Phospho-tau pSer396 (ThermoFisher, 44-752G); Rab7 (Abcam, ab50533) IF 1:500; Synaptophysin (Merck Millipore, MAB5258) IF 1:1000; Tsg101 (Genetex, GTX70255) IF 1:250, WB 1:1000; VPS4 (SantaCruz, sc-133,122) IF 1:100, WB 1:1000; secondary antibodies conjugated to Alexa
Fluor-488, -546, -647 (IF 1:500; Invitrogen) or to HRP (WB 1:2000; R\&D Systems, Minneapolis, MN).

Bafilomycin A (Sigma), torin 1 (Tocris) or rapamycin (Fisher BioReagents) were added to pre-warmed culture media at appropriate concentrations. Starvation media for induction of autophagy was 33\% Opti-MEM in Hank's Balance Salt solution (HBSS). A $\beta 1-40$ or A $\beta 1-42$ peptides (Tocris) were reconstituted in DMSO to $250 \mu \mathrm{M}$, sonicated for $10 \mathrm{~min}$ and followed by $15 \mathrm{~min}$ of centrifugation at $12 \mathrm{k} \mathrm{rpm}$ before adding the supernatant to the culture media for the depicted times. All experiments used $0.5 \mu \mathrm{M}$ of $\mathrm{A} \beta 1-40$ or $\mathrm{A} \beta 1-42$, except for $\mathrm{EM}$ and LAMP-1 positive vesicle size experiments that used $5 \mu \mathrm{M}$ and $1 \mu \mathrm{M}$ respectively.

\section{Cell immunofluorescence}

Cultured neurons at 12 DIV or N2a cells were fixed in $4 \%$ paraformaldehyde (PFA) in phosphate buffered saline (PBS) with $0.12 \mathrm{M}$ sucrose for $20 \mathrm{~min}$, permeabilized and blocked in PBS containing 2\% normal goat serum (NGS), $1 \%$ bovine serum albumin (BSA), and $0.1 \%$ saponin at room temperature (RT) for $1 \mathrm{~h}$, and then immunolabelled in $2 \%$ NGS in PBS overnight at $4{ }^{\circ} \mathrm{C}$. After appropriate washing, coverslips were mounted with SlowfadeGold (Invitrogen). Immunofluorescence was examined by confocal laser scanning microscopy (Leica TCS SP8 or Zeiss LSM 510). In multiple label experiments, channels were imaged sequentially to avoid bleed-through. Images were taken with Leica Confocal Software or Zeiss ZEN software and analysed with Image or Imaris 7.6. LAMP1-positive vesicles in pyramidal neurons were quantified by measuring the diameter of the five largest LAMP1-positive vesicles per cell, imaged by confocal microscopy in z-stacks, ( $\mathrm{n}=>45$ LAMP1-positive vesicles). All fluorescent labelling of cells was performed $n \geq 3$; and in the case of primary neurons from different embryos.

\section{Brain immunofluorescence}

Mice were anesthetized with isoflurane and perfused transcardially with saline followed by 4\% PFA in $0.1 \mathrm{M}$ PBS ( $\mathrm{pH}$ 7.4) at RT. After dissection, brains were postfixed by immersion in $4 \%$ PFA in $0.1 \mathrm{M} \mathrm{PBS}\left(\mathrm{pH} \mathrm{7.4)}\right.$ ) at $4{ }^{\circ} \mathrm{C}$ for $2 \mathrm{~h}$ or overnight. After fixation, brains were cut in $40 \mu \mathrm{m}$ thick sections with a sliding microtome. Sections were kept in storage buffer composed of 30\% sucrose and 30\% ethylene glycol in PBS at $-20{ }^{\circ} \mathrm{C}$. Free-floating sections were blocked for $1 \mathrm{~h}$ in RT with serum and triton-X and then incubated in primary antibodies overnight at $4{ }^{\circ} \mathrm{C}$, followed by appropriate fluorescent Alexa secondary antibodies for $1 \mathrm{~h}$ at RT.

\section{Western blot}

Medium was collected and centrifuged and cells were washed twice, harvested in ice cold PBS, and centrifuged. Cell pellets were lysed with $6 \%$ sodium dodecyl sulfate 
(SDS) containing $10 \mu \mathrm{l} / \mathrm{ml} \beta$-mercaptoethanol, sonicated, and then heated at $95{ }^{\circ} \mathrm{C}$ for $6 \mathrm{~min}$. After centrifugation, supernatants and medium were mixed with loading buffer, heated at $95{ }^{\circ} \mathrm{C}$ for $5 \mathrm{~min}$ and loaded into $10-20 \%$ Tricine gels (Invitrogen). Samples were subjected to electrophoresis and transferred to polyvinylidine difluoride membranes (Millipore). Membranes were blocked in PBS containing $0.1 \%$ Tween-20 (PBST) and 5\% milk, and incubated in primary antibodies overnight and then with HRP-conjugated secondary antibodies for $1 \mathrm{~h}$ diluted in PBS containing 0.1\% Tween-20 (PBST) and 5\% milk. The immunoreaction was visualized by a chemiluminescence system (Pierce or BioRad). Bands were quantified using Image Lab (Bio-Rad Laboratories). For visualization of $A \beta$, membranes were boiled in PBS for 5 min prior to blocking. For analysis of exosomes, WB was performed as above but without $\beta$ mercaptoethanol in the 6\% SDS lysis buffer.

For analysis of LC3 $\beta$ cells were lysed in RIPA buffer (Thermo Fisher Scientific) with protease inhibitor and phosphatase inhibitor (Thermo Fisher Scientific). Lysates with NuPAGE LDS sample buffer and NuPAGE reducing agent were loaded on NuPAGE 4-12\% BisTris gels and run with NuPAGE MES SDS buffer (Invitrogen).

For analysis of $\alpha$-synuclein in medium, total protein was extracted using a trichloroacetic acid (TCA)/acetone precipitation protocol. Briefly, freshly collected samples were cleared by centrifugation at $10000 \mathrm{rpm}$ for $10 \mathrm{~min}$ to pellet debris and intact cells. The supernatant was transferred to a new tube and added with $1 / 4$ volume of ice-cold $20 \%$ TCA followed by incubation on ice for $3 \mathrm{~h}$. The proteins were pelleted by centrifugation at $14000 \mathrm{rpm}$ and washed twice with cold acetone.

For native conditions, cell pellets were lysed on ice in NativePAGE sample buffer (1X, Life Technologies) containing 1\% digitonin (Life Technologies) and Halt proteinase inhibitor cocktail (1X, Thermo Scientific) by pipetting up and down and incubating on ice for $15 \mathrm{~min}$. Lysates were centrifuged at $20000 \mathrm{x}$ g for $30 \mathrm{~min}$ at $4{ }^{\circ} \mathrm{C}$ and protein concentrations of the supernatants were determined with BCA assay. Equal amounts of protein were loaded on a $3-12 \%$ NativePAGE Novex Bis-Tris gel (Life Technologies).

\section{Exosome isolation and analysis}

Exosomes were purified from cell culture medium by differential ultracentrifugation as described previously [30]. Briefly, Swe N2a cells were cultured and transfected for $48 \mathrm{~h}$ in exosome-free medium. Collected medium was depleted of cells and cellular debris by sequential low speed centrifugation. Exosomes were then isolated by centrifugation of the collected supernatant at $100,000 \times \mathrm{g}$ at $4{ }^{\circ} \mathrm{C}$ for $70 \mathrm{~min}$. The resultant pellet was washed in PBS and centrifuged for $70 \mathrm{~min}$ at $100,000 \times \mathrm{g}$ at $4{ }^{\circ} \mathrm{C}$.

\section{Statistical analysis}

Statistical analysis was performed with PRISM 6 software (Graph-Pad Software, San Diego, CA, USA) by using unpaired t-test or ANOVA with Tukey's multiple comparisons test or ANOVA with Dunnett's multiple comparisons test. All data are expressed as the mean \pm SD. Differences were considered significant at " $p<0.05,{ }^{* * *} p<0.01,{ }^{* * * *} p<0.001,{ }^{* * * * * *} p<0.0001$.

\section{Results}

\section{$A \beta$-dependent MVB enlargement}

Endogenous $A \beta 42$ is present in both dendrites and axons of cultured primary APP transgenic neurons and localizes especially with markers of late endosomes/MVBs [21]. In order to examine whether increased levels of $A \beta$ can lead to the enlarged endosomal phenotype seen in AD, MVB size was compared between APP/PS1 transgenic and wt primary mouse neurons. Cells were incubated with BSAgold $2 \mathrm{~h}$ (h) before fixation to confirm identity of the endocytic compartments. Remarkably, electron micrographs showed a significantly greater MVB diameter $(52 \%$ increase; $p<0.001)$ in APP/PS1 transgenic compared to wt neurons at 12 days in vitro (DIV) (Fig. 1a and b) consistent with the larger diameter of endosomes described in human AD. Since full length APP, $\beta$-CTFs, A $\beta$ and the presenilin mutation in the APP/PS1 transgenic neurons potentially all could be the cause of this effect, wt neurons at 12 DIV were treated with freshly prepared human synthetic $A \beta 1-40$ or $A \beta 1-42$ for 48 h, to test if $A \beta$ was sufficient to induce the endosomal enlargements. The neurons demonstrated a $69 \%$ and $114 \%$ increase in the diameter of MVBs with $A \beta 1-40$ or $A \beta 1-42$ treatment, respectively $(p<0.001$; Fig. $1 \mathrm{c}$ and $\mathrm{d})$ as measured on EM images compared to controls. Further, an increased size by $165 \%$ of LAMP1-positive late endosomes/lysosomes was already evident by immunofluorescent labelling at $3 \mathrm{~h}$ in pyramidal neurons treated with $\mathrm{A} \beta 1-42(p<0.0001$, Fig. $1 \mathrm{e}$ and f). LAMP1-changes at different time points of $A \beta 1-42$ treatment, ranging from $30 \mathrm{~s}$ to $48 \mathrm{~h}$, are shown in Additional file 2: Figure S1B. Taken together, our results indicate that enlarged MVBs, one of the earliest pathological features in $\mathrm{AD}$, can be caused by $\mathrm{A} \beta$, which however does not rule out important contributions also of other APP components such as $\beta$-CTFs.

\section{Fibril-like structures in endocytic organelles of wild-type neurons treated with $A \beta$}

Interestingly, fibril-like structures were apparent by EM in endocytic organelles of wt primary neurons incubated with synthetic human $A \beta 1-42$ for 48 h that were not seen in untreated neurons (Fig. $2 \mathrm{a}$ ), and were more prominent in neurons treated with $A \beta 1-42$ than $A \beta 1-40$. For comparison, $A \beta 1-42$ fibrilized in vitro showed similar size and morphology of fibrils on EM as in the endocytic vesicles 


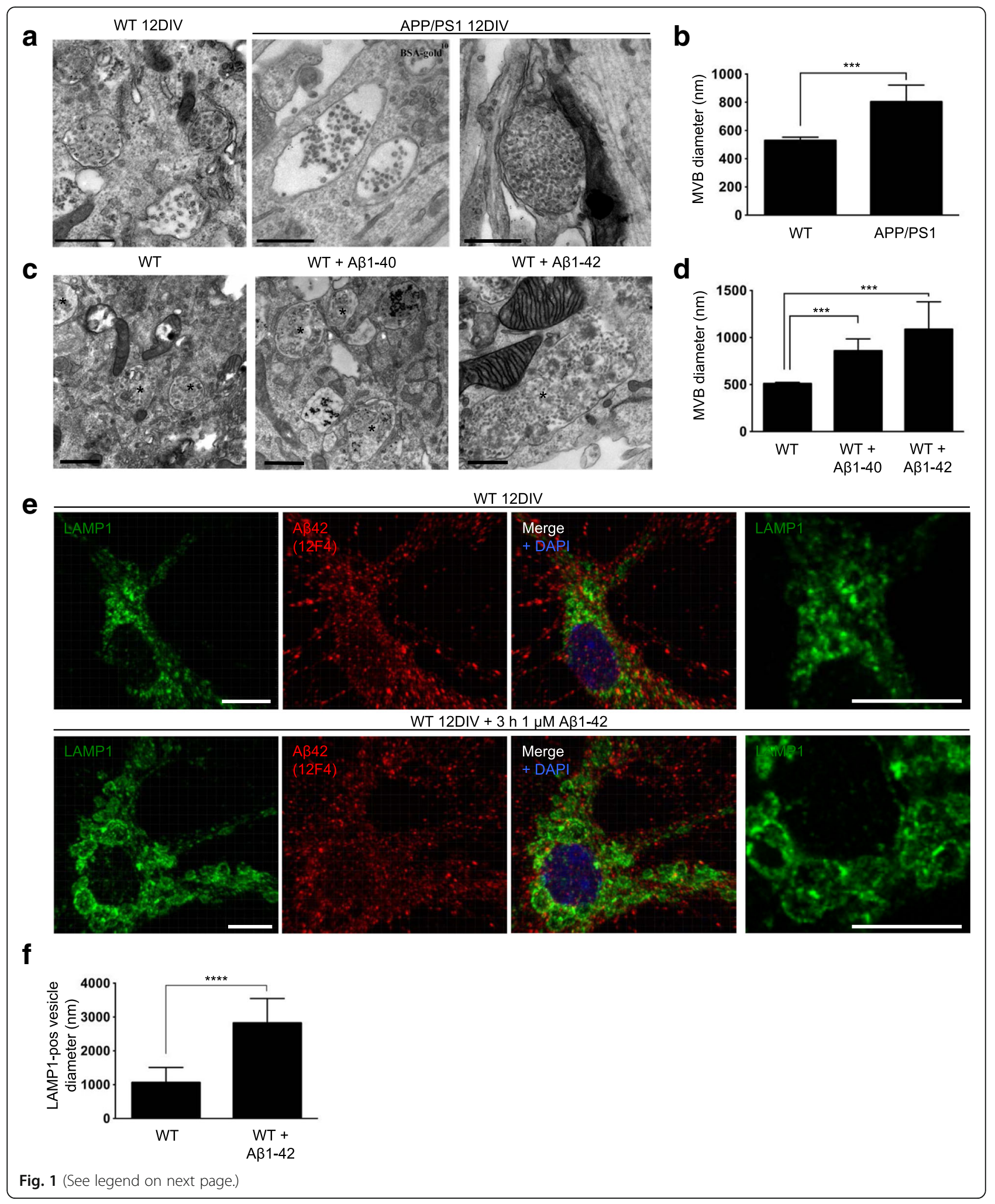




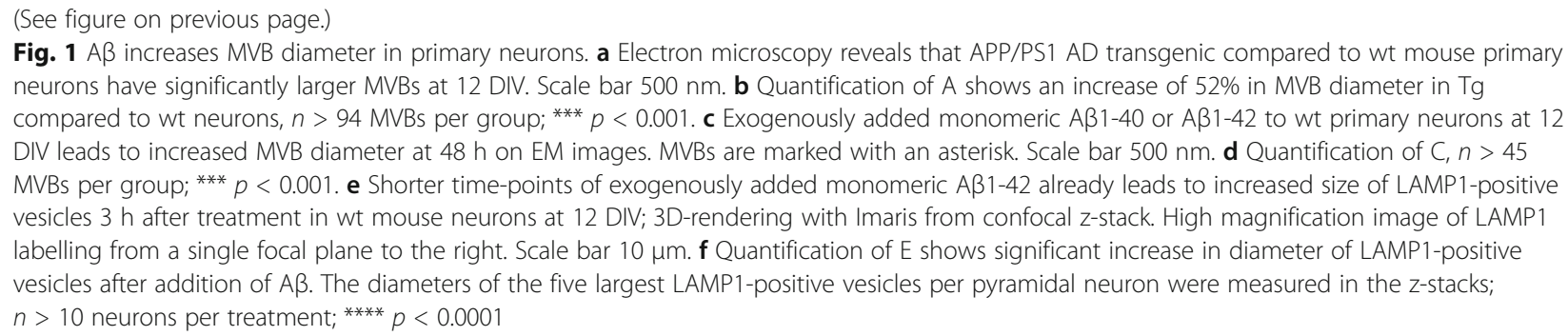

(Fig. 2b). Loss of endolysosomal impermeability was also seen with A $\beta 1-42$ treatment of neurons with BSA-gold leaking out into the cytoplasm (Fig. 2c). To further investigate the fibril-like structures, wt murine neurons were treated with elevated levels of human A $\beta 1-42$ at different time points and immunolabelled with the conformational dependent $\mathrm{A} \beta$ antibody $\mathrm{OC}$ to label amyloid fibrils and fibrillar oligomers [31] and antibody 6E10 to specifically label the added human $A \beta$. Using the same parameters as in the EM experiments, neurons treated with $A \beta 1-40$ only led to weak $\mathrm{OC}$ antibody labelling compared to vehicle treated cells, while A $\beta 1-42$ treated neurons showed robust OC labelling (Additional file 3: Figure S2).

Already at 45 min of treatment with $0.5 \mu \mathrm{M}$ A $\beta 1-42$ (Fig. $2 \mathrm{~d}$ ) and up to $24 \mathrm{~h}$ of incubation, antibodies OC and $6 \mathrm{E} 10$ revealed an almost completely overlapping vesicular pattern of labelling, indicating that the amyloid fibrils and/or fibrillar oligomers consisted of A 1 1-42, which was particularly prominent along neuronal processes. Of note, OC labelling increased in intensity with time of treatment with $A \beta 1-42$. Interestingly, at $48 \mathrm{~h}$ the $\mathrm{OC}$ positive structures were enlarged and elongated, displaying a part that was human $\mathrm{A} \beta$ antibody $6 \mathrm{E} 10$ positive and an extension that was $6 \mathrm{E} 10$ negative (Fig. 2e). Surface labelling of non-permeabilized cells revealed that the elongated OC labelling at $48 \mathrm{~h}$ was now to a certain extent extracellular, whereas the punctate OC and 6E10 co-labelling at $24 \mathrm{~h}$ was generally intracellular (Fig. 2f). This suggests that with time, fibrils extend out of neurites into the extracellular space and/or that organelles containing the fibrils fuse with the plasma membrane. To better define the subcellular site of $A \beta$ aggregation, cells were double labelled with $\mathrm{OC}$ antibody and the late endosomal/lysosomal marker LAMP1. At 45 min colocalization with OC was evident in small LAMP1-positive vesicles in the processes but not in the larger LAMP1-positive vesicles in the cell soma (Additional file 4: Figure S3A). Since lysosomes normally do not localize to axons and dendrites, other than their very proximal part, this suggests that $A \beta 42$ starts to aggregate in late endosomes/MVBs of neurites. At $48 \mathrm{~h}, \mathrm{OC}$ and LAMP1 still colocalized mainly in neuronal processes, but in LAMP1-positive structures that now appeared somewhat enlarged and irregular in their shape. Elongated OC-positive structures could be seen extending out from the more punctate LAMP1 labelling (Fig. $2 \mathrm{~g}$ and
Additional file 4: Figure S3A). The late endosomal marker Rab7 indicated that at least a subset of the vesicular OC labelling at $24 \mathrm{~h}$ colocalized with Rab7 positive late endocytic compartments in neurites (Additional file 4: Figure S3C). Taken together these data indicate that $A \beta 1-42$ can be taken up by neurons in culture and forms amyloidogenic fibrils and/or fibrillar oligomers in late endocytic compartments particularly within neuronal processes that eventually appear to extend extracellularly.

\section{$A \beta 1-42$ induces changes in the native state of ESCRT-III complex component CHMP2B}

Given prior evidence supporting that sorting via the MVB pathway was impaired by $A \beta$ accumulation in cultured $A D$ transgenic neurons and that $A \beta$ dependent translocation into MVBs seemed affected [21], we next investigated possible dysfunction of the ESCRT pathway in models of AD. In APP/PS1 transgenic primary neurons $A \beta 42$ was found associated with CHMP2B-positive vesicles (Fig. 3a). In young 3-month-old Tg19959 mice, a different transgenic mouse model of $\beta$-amyloidosis harbouring the Swedish and Indiana APP mutations, CHMP2B immunolabelling was most prominent in the area of hippocampus and entorhinal cortex that also expressed increased levels of A $\beta / A P P$ (Additional file 5: Figure S4A-B). Although levels of total CHMP2B and VPS4 were not significantly changed in wt compared to APP/PS1 primary neurons lysed in 6\% SDS (Additional file 5: Figure S4C), levels of high molecular weight complexes of CHMP2B on blue native polyacrylamide gel electrophoresis were increased in APP/PS1 neurons treated with $\mathrm{A} \beta 1-42$ for $3 \mathrm{~h}$ (Fig. $3 \mathrm{~b}$ ). Other ESCRT proteins were not resolved on native gels, likely due to masking of antibody epitopes under native conditions.

\section{ESCRT components localize to amyloid plaques}

Since AD transgenic neurons showed an increased diameter of MVBs and treatment with A $\beta 1-42$ led to prominent fibril-like structures in late endocytic organelles, and as prior immuno-EM work has indicated early $A \beta$ accumulation in dystrophic neurites [10], we next examined whether aggregating $\mathrm{A} \beta 42$ in endosomes might lead to the presence of ESCRT components in amyloid plaques. Indeed, APP/PS1 transgenic mice with plaque pathology demonstrated that the ESCRT-III associated protein VPS4 


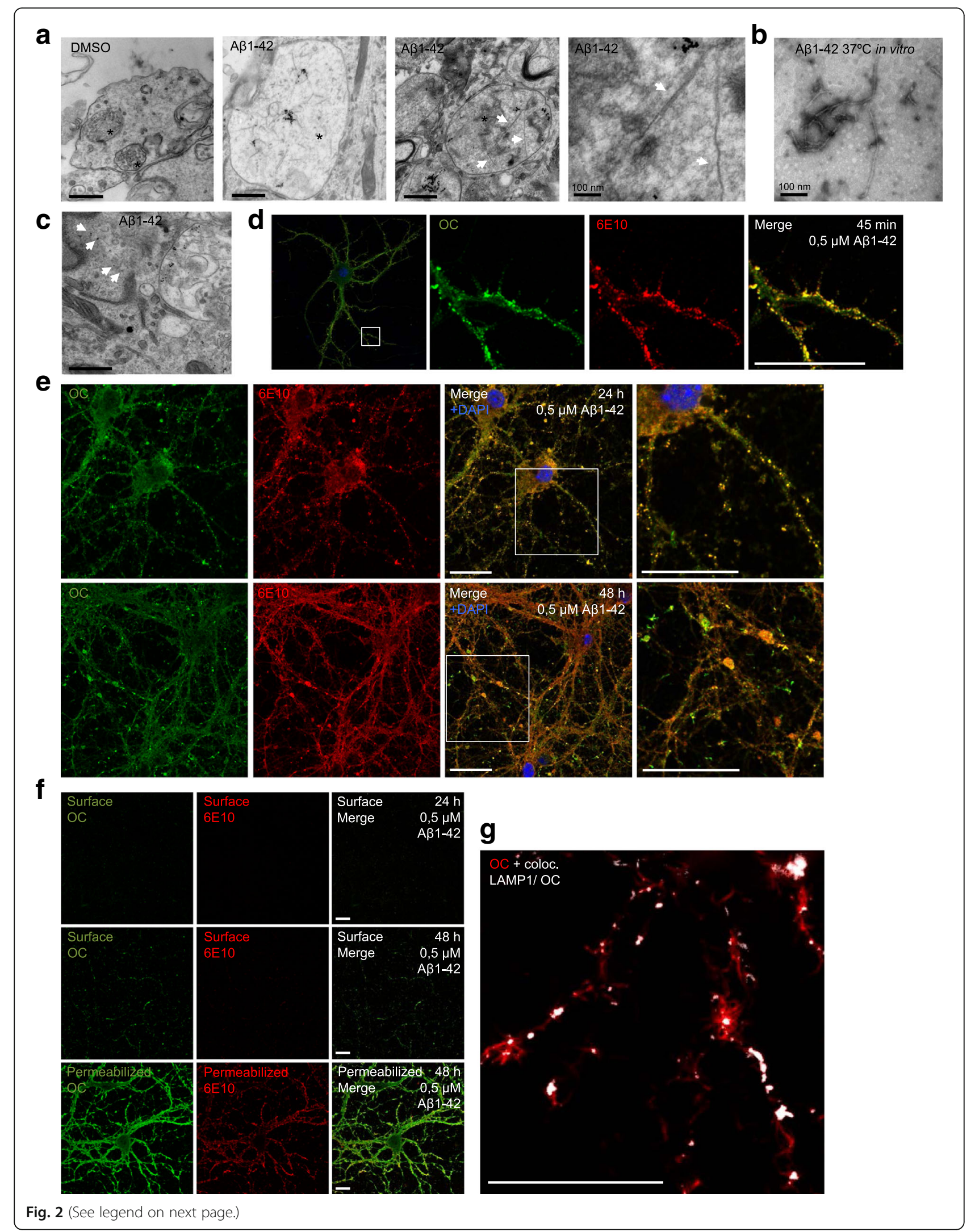


(See figure on previous page.)

Fig. 2 Fibril-like structures in endocytic organelles of wild-type neurons treated with AB1-42. a Wt primary neurons treated at 12 DIV with $A \beta$ for $48 \mathrm{~h}$ induced fibril-like structures in endocytic organelles with A 1 1-42. BSA-gold was added to cells $2 \mathrm{~h}$ before fixation to delineate endocytic organelles (marked with asterisk). Scale bar $500 \mathrm{~nm}$. High magnification image to the right, scale bar $100 \mathrm{~nm}$. b A $1-42 \mathrm{peptides}$ incubated in vitro at $37^{\circ} \mathrm{C}$ for $1 \mathrm{~h}$ to induce fibril formation, imaged with EM. Scale bar $100 \mathrm{~nm}$. c BSA-gold (white arrows) was found in the cytosol in A 1-42 treated neurons, indicating loss of endolysosomal impermeability due to Aß1-42. Scale bar $500 \mathrm{~nm}$. d OC antibody labelling for fibrillar oligomers and/or fibrils is seen in a vesicular pattern in processes after 45 min treatment with $0.5 \mu \mathrm{M}$ of AB1-42 and colocalizes with human $A \beta$ antibody $6 E 10$ confirming that fibrils consist of the added human AB1-42. Scale bar $10 \mu$ m. e Feeding $0.5 \mu M$ of $A \beta 1-42$ to wt primary neurons at 12 DIV at $24 \mathrm{~h}$ vs $48 \mathrm{~h}$. At $24 \mathrm{~h}$ most of the OC labelling was also antibody $6 \mathrm{E} 10$ positive. At $48 \mathrm{~h}$ the outer aspects of OC positive structures were 6 E10 negative. Scale bar $20 \mu \mathrm{m}$. f Weak surface labelling of non-permeabilized neurons shows that OC and 6 E10 antibody positive structures were intracellular after $24 \mathrm{~h}$ of treatment with Aß1-42 (upper panel). At $48 \mathrm{~h}$ extracellular OC antibody labelling was now more visible consistent with penetration of the plasma membrane by the elongated OC positive fibrils (middle panel). Strong OC and $6 \mathrm{E} 10$ antibody labelling of permeabilized cells after fixation but before immunolabelling, shows that the vast majority of added human A $1-42$ (antibody 6E10) and OC antibody positive fibrils and/or fibrillar oligomers are inside neurons (lower panel). Scale bar $20 \mu \mathrm{m}$. $\mathrm{g}$ After $48 \mathrm{~h}$ of treatment with $0.5 \mu \mathrm{M}$ Aß1-42, OC antibody labelling was seen extending out from LAMP1-positive structures in the processes. The image shows OC with the superimposed colocalizing channel for LAMP1 and OC. For the complete image with separate channels see Additional file 3: S2A. Scale bar $20 \mu \mathrm{m}$

was markedly increased in plaques (Fig. 3c and Additional file 5: Figure S4D), where it partially colocalized with A 342 . ESCRT-I component Tsg101, a marker of MVBs, also showed increased labelling in plaques (Fig. 3d). In contrast, labelling of CHMP2B and the earlier ESCRT-0 component Hrs appeared decreased in plaques compared to surrounding brain parenchyma (Additional file 5: Figure S4E-F). Brain sections were also co-labelled with an antibody against clavestin-1 and 2 (Fig. 3d), which are neuron-specific proteins in the endo-lysosomal pathway [32]. The strong colocalization between Tsg101 and clavesin- 1 and 2 in amyloid plaques supports the neuronal origin of ESCRT components in plaques. Moreover, much of the strong $\mathrm{A} \beta 42$ labelling outside of plaques in $\mathrm{AD}$ transgenic brain occurred in vesicle-like structures of dystrophic neurites that also contained clavesin- 1 and 2 and Tsg101, consistent with accumulation of $A \beta 42$ within endosomal compartments of neurons. To confirm these results in a different $A D$ transgenic mouse model of $\beta$ amyloidosis, $\operatorname{Tg} 19959$ mice were examined with the onset of plaque pathology. In early plaques of 3-month-old Tg19959 mice Tsg101 (Fig. 3e) and VPS4 (not shown) also colocalized strongly with $A \beta 42$.

\section{Blocking VPS4A increases intracellular accumulation and decreases secretion of $A \beta$}

In order to model the effect of dysfunctional ESCRTdependent MVBs on $A \beta$ accumulation, a dominant negative, E228Q ATPase-deficient form of VPS4A (dnVPS4A) was expressed for $24 \mathrm{~h}$ in N2a neuroblastoma cells harbouring stably transfected human Swedish mutant APP. N2a cells were used here because of their high transfection efficiency compared to primary neurons. To assess that $\mathrm{N} 2$ a cells react to $\mathrm{A} \beta 1-42$ in a similar manner as primary neurons, N2a cells were treated with exogenously added $A \beta 1-42$ for different time points. N2a cells treated with A $\beta 1-42$ also exhibited increased size of LAMP1positive vesicles (Additional file 6: Figure S5). The ATPase
VPS4 is a key component of the ESCRT machinery as it is the only energy-consuming enzyme, promotes disassembly and recycling of ESCRT-III oligomers, and is recruited to the ESCRT-III complex by direct interaction with CHMP2B. We found that the expression of dnVPS4A markedly increased the intracellular pool of $\mathrm{A} \beta$ by $424 \%$ $(p<0.001$, Fig. $4 \mathrm{a}$ and $\mathrm{d})$ while concurrently decreasing the amounts of $\mathrm{A} \beta$ secreted into the medium by $87 \%$ $(p<0.0001$, Fig. 4c and d). DnVPS4A also increased higher molecular weight bands between $17 \mathrm{kDa}$ and $34 \mathrm{kDa}$ that might represent $\mathrm{A} \beta$ oligomers within cells (Fig. 4a) as they were not seen with C-terminal specific APP antibody 369 (Fig. 4b). In addition, dnVPS4A increased the levels of APP within cells by $149 \%(p<0.05)$ and secreted APP $\alpha$ in conditioned media by $149 \%$ $(p<0.05)$. Overexpression of wild type VPS4A (wtVPS4A) also significantly reduced secretion of $\mathrm{A} \beta$ by $72 \%$ $(p<0.001)$, although not to the extent of the dominant negative construct. Such a partially dominant negative effect of over-expressing wtVPS4 has been described [28].

Confocal immunofluorescence microscopy of Swe N2a cells transfected with dnVPS4A confirmed the increase of $A \beta$ and full-length APP (Fig. 4e). Increased labelling by immunofluorescent microscopy with the conformational antibody OC in dnVPS4A-transfected cells confirmed the increase in $A \beta$ oligomers and showed that the fibrillar oligomers and/or fibrils labelled by antibody OC colocalized with enlarged vesicles labelled positive for dnVPS4A protein and flotillin-1 (Fig. 4f and g). Triple labelling revealed that $A \beta 42$ accumulated in enlarged vesicles positive for the MVB marker Tsg101 in dnVPS4A expressing cells labelled by the FLAG-tag (Fig. 4h). Thus, dysfunctional MVBs accumulate $A \beta 42$ that, at least in part, is in an oligomeric and/or fibrillar form. In contrast to effects on $A \beta$ and in agreement with a prior report [28], dnVPS4A increased secretion of $\alpha$-synuclein in $\alpha$-syn N2a cells without altering the total pool of intracellular $\alpha$-synuclein (Additional file 


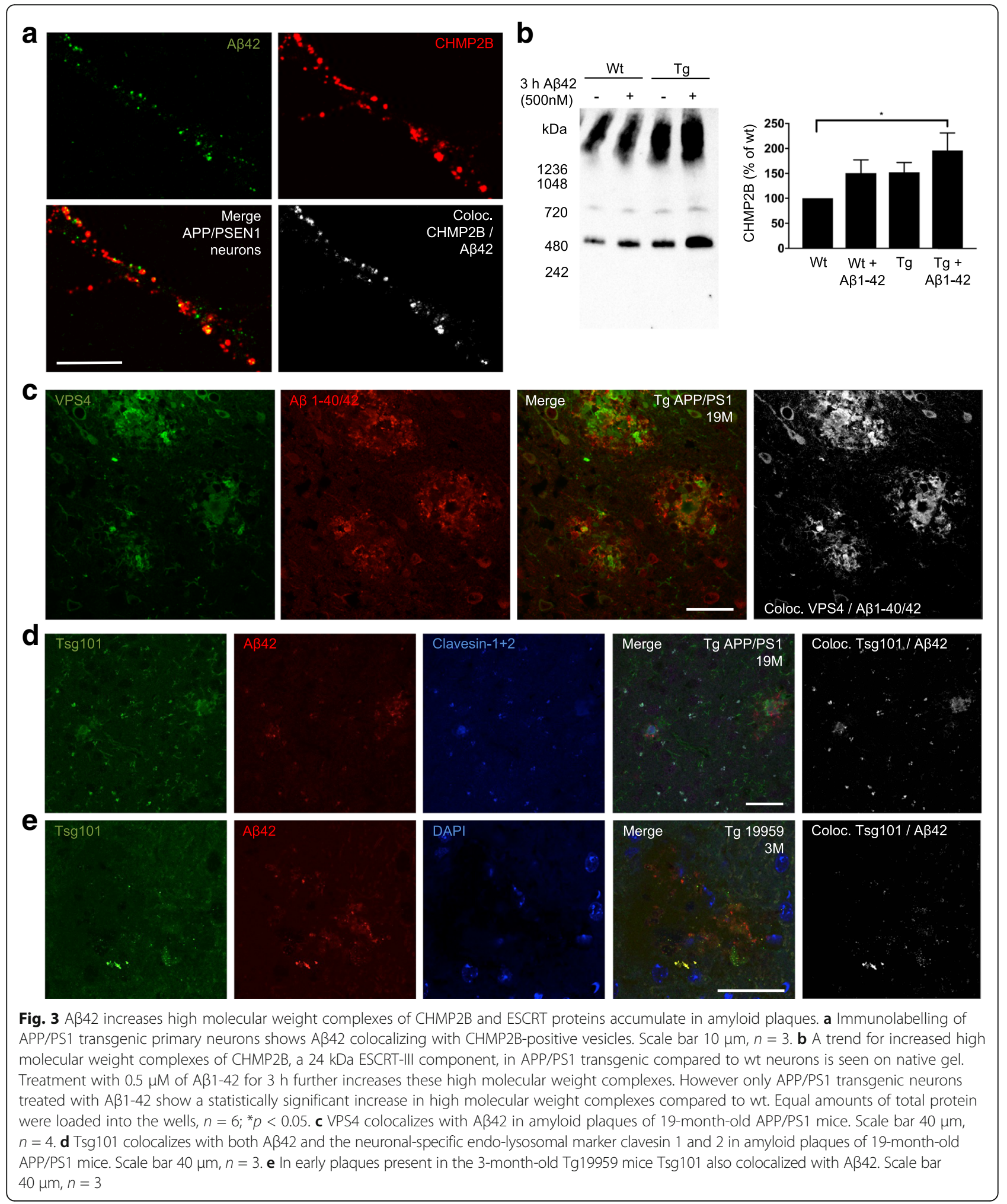

7: Figure S6). Since the CMV-FLAG-dnVPS4A induced toxicity in primary neurons, we constructed a plasmid under the weaker synapsin promoter. Expressing dnVPS4A under this synapsin promoter in wt or APP/PS1 primary neurons showed increased labelling of $\mathrm{A} \beta 42$ (Fig. 4i), supporting that dysfunctional ESCRT-dependent MVB formation leads to increased levels of $A \beta$ within neurons. 


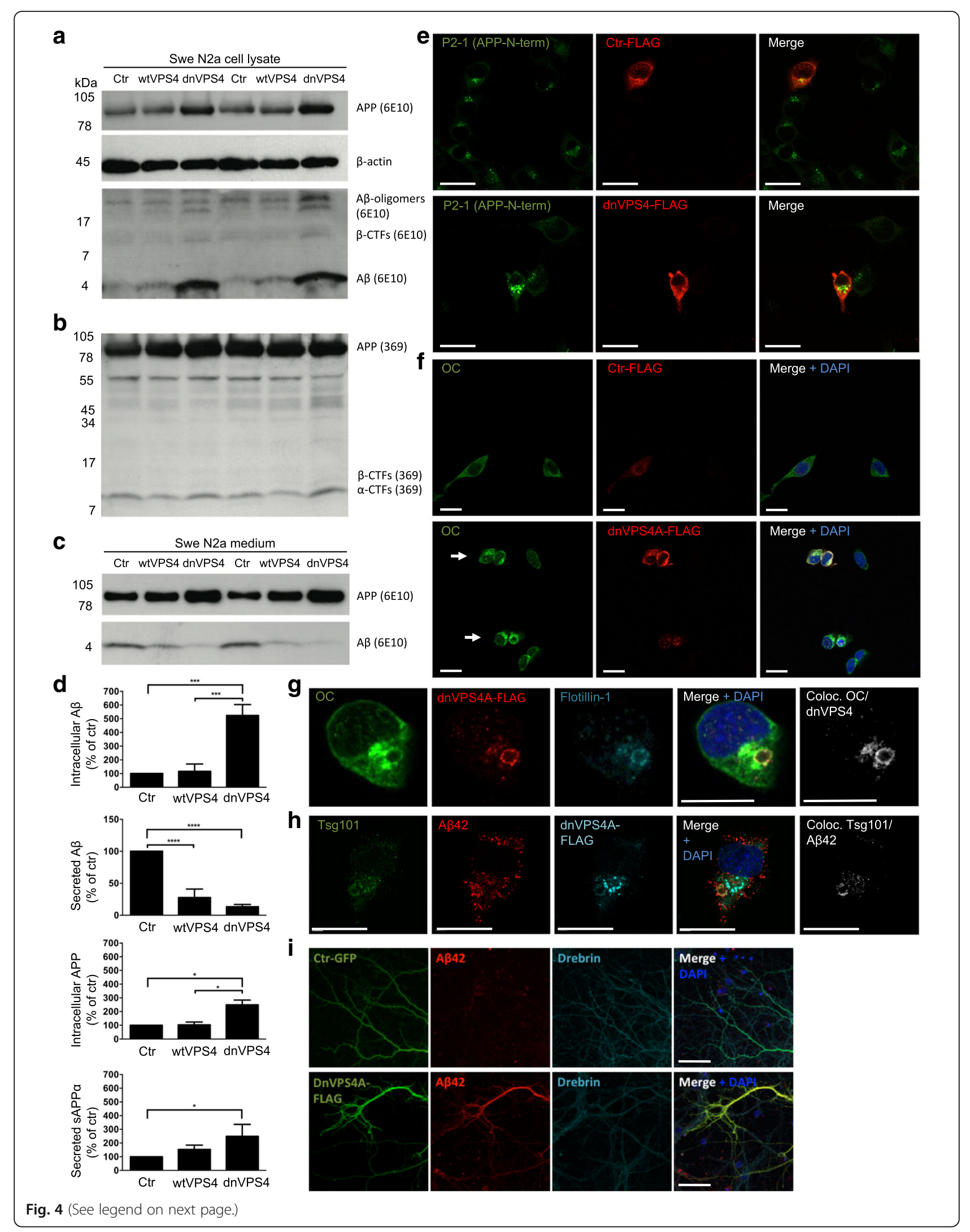




\begin{abstract}
(See figure on previous page.)
Fig. 4 DnVPS4A causes increased accumulation and reduced secretion of Aß42. Expression of control plasmid (ctr), wtVPS4A (wtVPS4) or the ATP hydrolysis deficient mutant dnVPS4A (dnVPS4) in Swe N2a cells (A-H) or wt primary mouse neurons (I) for $24 \mathrm{~h}$. a Representative Western blot of APP, SDS-stable oligomeric A $\beta$ species, $\beta$-CTFs and monomeric A $\beta$ in cell lysate probed with antibody 6 E10, and $\beta$-actin for protein normalization. b Western blot analysis of full length APP, $\beta$-CTFs and a-CTFs in cell lysate probed with the C-terminal specific APP antibody 369. c Western blot analysis of secreted $\mathrm{AAPP}(\mathrm{SAPPa}$ ) and $\mathrm{A} \beta$ in cell medium with antibody $6 \mathrm{E} 10 . \mathbf{d}$ Densitometric quantification of $\mathrm{A}$ and $\mathrm{C}$ demonstrates that expression of dnVPS4, but not wtVPS4, increases intracellular A $\beta$ compared to ctr. On the other hand, both wtVPS4A and dnVPS4A reduces secreted A $\beta$ compared to $c t r$, although to a greater extent with dnVPS4A. DnVPS4 increases both cellular and secreted APP. Values are normalized against actin and expressed as percentage of control, $n>3 ;{ }^{*} p<0.05,{ }^{* *} p<0.01,{ }^{* *} p<0.001$, ${ }^{* * *} p<0.0001$. e Cellular full length APP is increased in cells transfected with dnVPS4A-FLAG (lower panel) compared to control plasmid Ctr-FLAG (upper panel). Scale bar $25 \mu \mathrm{m}$. f Antibody OC labelling of fibrillar oligomers and fibrils is increased in cells transfected with dnVPS4A (arrows) compared to control plasmid. Scale bar $25 \mu \mathrm{m}$. g Antibody OC labelling in dnVPS4-transfected cells is associated with enlarged vesicles positive for flotillin-1. Scale bar $15 \mu \mathrm{m}$. $\mathbf{h}$ Aß42 accumulation in vesicles positive for ESCRT protein Tsg101 in dnVPS4A-transfected cells. Scale bar $25 \mu \mathrm{m}$. i Wt primary neurons at 12 DIV transfected with synapsin-dnVPS4A-FLAG or control synapsin-GFP plasmid for $24 \mathrm{~h}$, immunolabelled for A 42 and the post-synaptic protein drebrin shows that Aß42 labelling is increased with expression of dnVPS4A but not with control plasmid. Scale bar $50 \mu \mathrm{m}$
\end{abstract}

Increased cellular levels of $A \beta$ with dysfunctional MVBs is mimicked by inhibiting lysosomal degradation

The increased intracellular levels of $A \beta$ with dnVPS4A could be due to changes in the production of $A \beta$, reduced secretion and/or reduced fusion of MVBs with the lysosome for degradation. In order to investigate the turnover of APP and $A \beta$, Swe N2a were treated with the protein synthesis inhibitor cycloheximide (Additional file 8: Figure S7A-B and Additional file 9: Figure $\mathrm{S} 8 \mathrm{D}$ ). This revealed a rapid turnover of APP in cell lysates with a half-life of about $45 \mathrm{~min}$, while cellular $\mathrm{A} \beta$ had a half-life of about $4 \mathrm{~h}$. In contrast, the degradation of APP and $\mathrm{A} \beta$ in conditioned media was slower, not reaching $50 \%$ of control levels within $6 \mathrm{~h}$ of cycloheximide treatment. To investigate the role of lysosomal degradation, Swe N2a cells were treated for $24 \mathrm{~h}$ with $5 \mathrm{nM}$ bafilomycin A1 (BafA1), which inhibits the vacuolar $\mathrm{H}+\mathrm{ATPase}$. BafA1 treatment had the same effects on $\mathrm{A} \beta$ as dnVPS4A, markedly increasing intracellular levels of $A \beta$ and reducing the secretion of $A \beta$ (Fig. 5a-b and Additional file 9: Figure S8A-D). These results suggest that dnVPS4A blocks MVBs with A $\beta$ on route to lysosomes for degradation. Consistently, when the endo-lysosomal $\mathrm{pH}$ gradient was blocked with BafA1, dnVPS4A transfected cells no longer showed higher cellular levels of $A \beta$ than the wtVPS4A or GFP transfected cells (Fig. 5c). Hence, when the ability of lysosomes to degrade $A \beta$ is abolished, blocking $A \beta$ on route to the lysosomes via dnVPS4 does not lead to further $A \beta$ accumulation.

To investigate the secretion of $A \beta$ via fusion of MVBs with the plasma membrane and concomitant release of exosomes, exosomes from dnVPS4A-transfected Swe N2a cells were isolated and analysed (Fig. 5d). Secretion of exosomes was not prevented but instead increased by dnVPS4A in Swe N2a cells, possibly due to upregulation of ESCRT independent (CD63 dependent) MVB formation [33-35].

\section{Blocking ESCRT dependent ILV formation increases pathological tau phosphorylation}

A major question in $\mathrm{AD}$ is how $\mathrm{A} \beta$ links to tau pathology. MVBs are necessary for the sequestration of GSK3 [36] which phosphorylates tau at serine 396 (S396). Both elevated tau phosphorylation at S396 [37] and hyperactive GSK3 is implicated in AD [38, 39]. Therefore, we examined the effects of dnVPS4A on tau phosphorylation. Tau phosphorylation at residue S396 was significantly increased by $56 \%$ with dnVPS4A ( $p<0.05$; Fig. $6 \mathrm{a}$ and b), suggesting increased activation of GSK3 $\beta$ and increased GSK3 $\beta$ dependent phosphorylation of tau caused by dysfunctional ESCRT dependent MVBs. Immunofluorescence microscopy revealed increased GSK3 $\beta$ labelling of cells upon dnVPS4A transfection (Additional file 10: Figure S9A), although changes in total GSK3 $\beta$ or phosphorylated GSK3 $\alpha / \beta$ (S21/9) levels were not detected by Western blot in cell lysates of Swe N2a cells transfected with dnVPS4A (Additional file 10: Figure S9B). One possible explanation for this apparent discrepancy is that the active GSK3 $\beta$ in the cytosol and early endosomes (facing the cytosol) is easier to visualize with immunofluorescence than the sequestered GSK3 $\beta$ inside the ILVs of MVBs.

\section{Autophagy induction partially rescues the intracellular accumulation of $A \beta$}

Since autophagic organelles are markedly increased in $\mathrm{AD}$ and autophagy is thought to be impaired in the disease [14], we next examined LC3 $\beta$-II and p62, markers of autophagy, in dnVPS4A transfected cells accumulating intracellular A $\beta$. Expression of dnVPS4A in Swe N2a cells showed increased levels of LC3 $\beta$-II, which correlate with increased numbers of autophagosomes in the cell, by $35 \%(p<0.05$, Fig. 7a) and increased levels of $\mathrm{p} 62$ by $52 \%$ ( $p<0.05$, Fig. 7b). Inducing autophagy by $1 \mu \mathrm{M}$ Rapamycin ( $p<0.01$, Fig. 7c), 250 nM Torin1 or starvation (Fig. $7 d$ ) reduced the dnVPS4A-induced increase in intracellular $A \beta$. Thus, in the setting of dysfunctional MVBs with $A \beta$ that is inefficiently trafficked to 


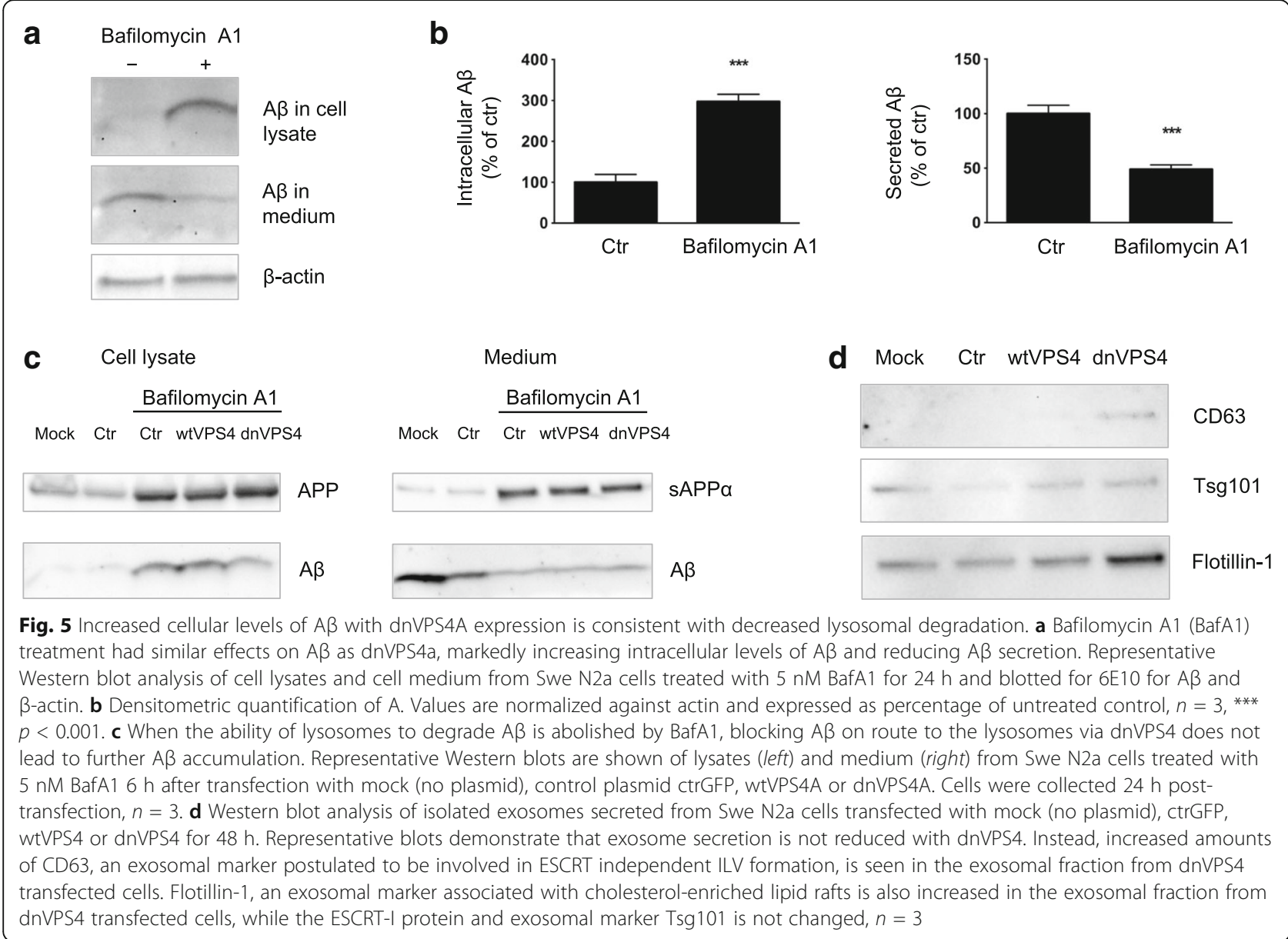

lysosomes for degradation and/or inefficiently secreted, stimulation of autophagy is associated with decreased cellular $\mathrm{A} \beta$.

\section{Discussion}

Over the past years, the view of the role of $A \beta$ in the pathogenesis of $\mathrm{AD}$ has been changing. Rather than merely aggregation of extracellular $A \beta$, a complex and interrelated biology of intra- and extra-cellular pools of $A \beta$ has emerged. Progressive intraneuronal $A \beta$ accumulation and impaired secretion of $A \beta$ were reported in AD transgenic neurons with time in culture $[9,40]$ and plaqueindependent, $A \beta$-dependent synapse damage and memory impairment correlated with this intracellular pool of $A \beta$ but not plaques in AD-transgenic mice [41]. Our working hypothesis is that dystrophic neurites with accumulating intraneuronal $A \beta$, initially within MVBs, are a nidus of plaque formation [10], with an important contribution of secreted $A \beta$ originating also from hyperactive neurons.
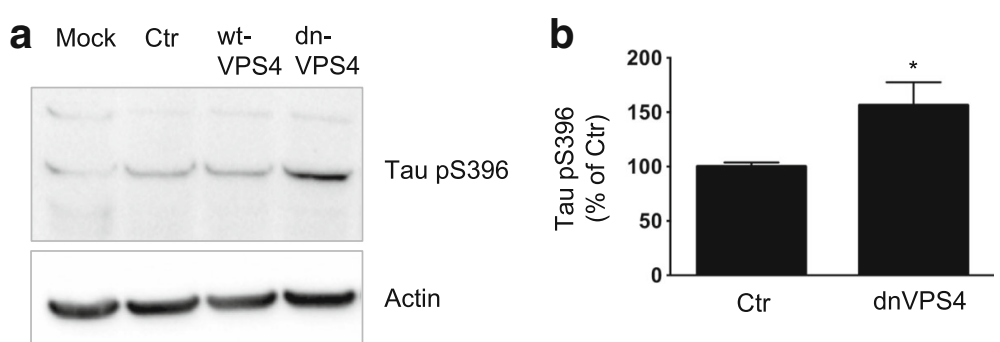

Fig. 6 Blocking ESCRT dependent ILV formation increases tau phosphorylation at serine 369 (S396). a Western blot of transfected N2a Swe cells demonstrates increased tau phosphorylation at S396 with expression of dnVPS4A. b Quantification of A shows a 56\% increase in levels tau phosphorylated at S396 with dnVPS4A; values are normalized against actin and expressed as percentage of ctrGFP, $\left(n=5,{ }^{*} p<0.05\right)$ 

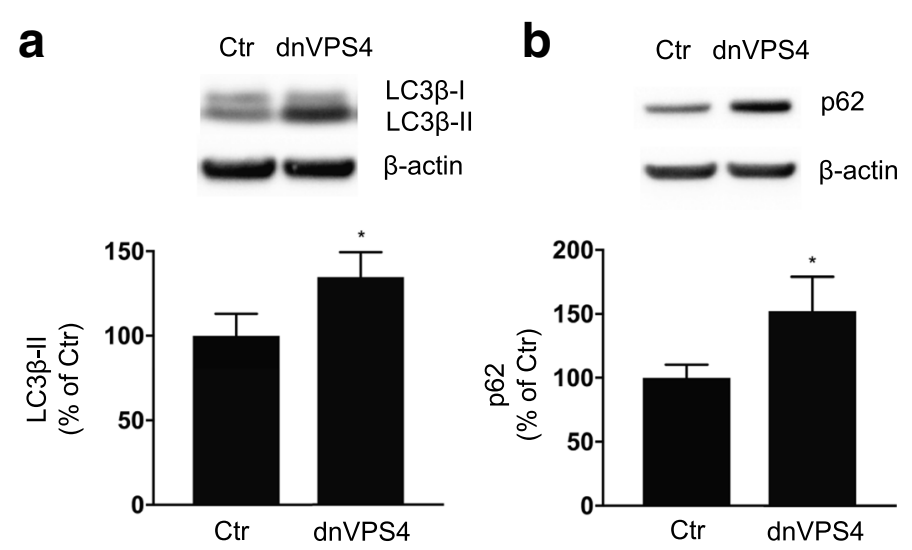

Rapamycin $\frac{\text { Mock }}{-+} \frac{\text { Ctr }}{-} \frac{\text { wtVPS4 }}{-+} \frac{\text { dnVPS4 }}{-+}$

$(18 \mathrm{~h})$
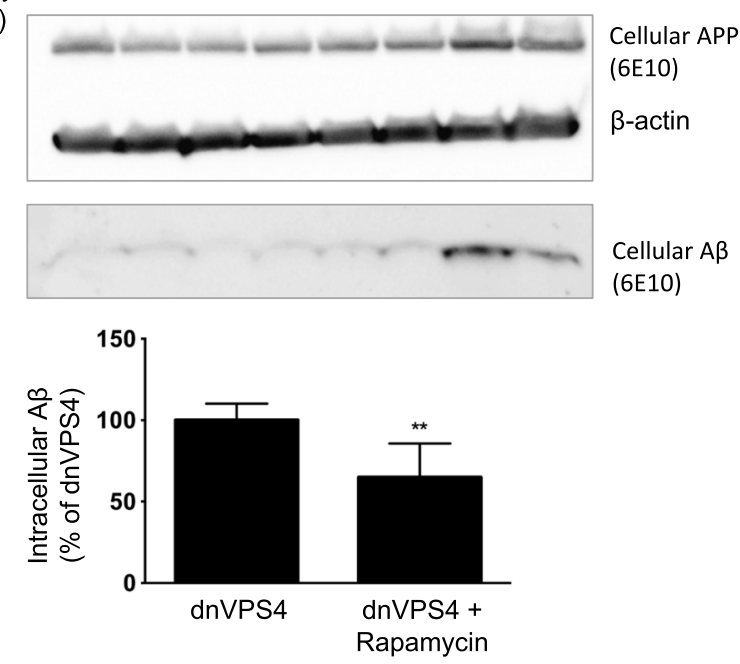

d
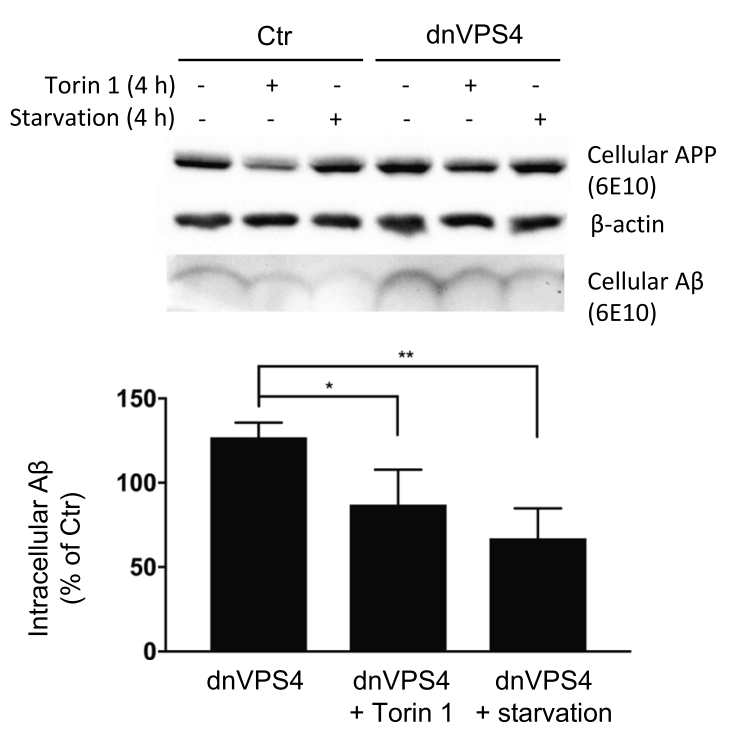

Fig. 7 (See legend on next page.) 


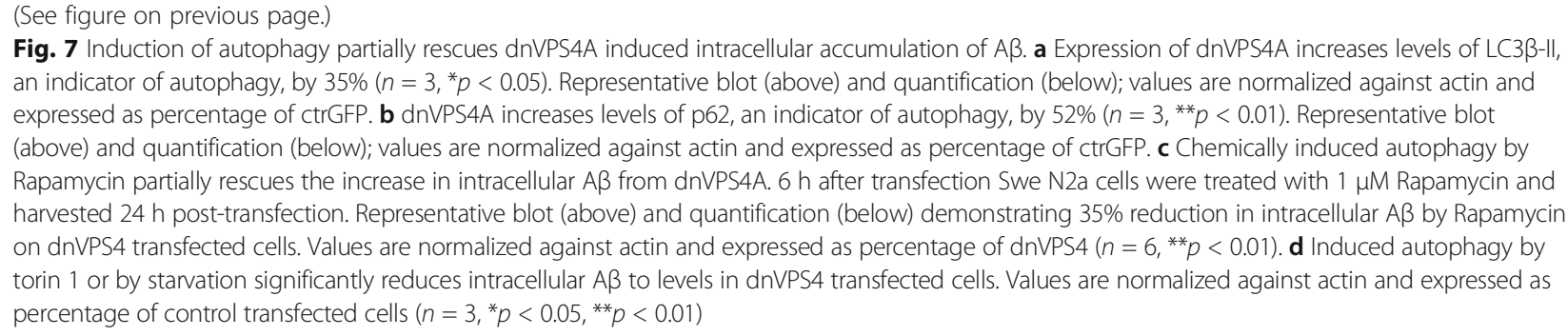

Here we provide novel molecular insights into endosomal alterations with $\mathrm{AD}$ pathogenesis. Enlarged endosomes have been observed to be among the earliest cellular changes in $\mathrm{AD}$ and the related $\mathrm{AD}$ pathology that develops in Down syndrome [12]. It has been reported that the enlarged phenotype in early endosomes and lysosomes in $A D$ is independent of $A \beta$ and instead only dependent on APP $\beta$-CTFs [42, 43]. We now provide evidence that MVB size is increased in AD transgenic neurons, and that this phenotype of increased late endosomal size can be recapitulated in wt neurons with addition of exogenous $A \beta$. These data support that $A \beta$ can induce endosomal enlargement, but do not exclude an important role also for APP $\beta$-CTFs. Although we only measured the size of MVBs with EM, it is likely that also other endocytic compartments including lysosomes and early endosomes were affected. The large LAMP1-positive vesicles seen and measured on confocal images (Fig. 1f) with $A \beta$ treatment, likely also include lysosomes and autolysosomes.

We show by EM fibrillar-like structures inside abnormal MVBs/late endocytic/lysosomal compartments in neurons treated with $A \beta 1-42$, and immunofluorescent labelling further indicates that MVBs/late endocytic compartments contain aggregated $A \beta 1-42$. We cannot fully exclude the possibility that these aggregates begin to form in the cell culture medium and then are taken up by the cells. However, the acidic $\mathrm{pH}$ environment and high peptide concentration in a limited space promote amyloid aggregation [44], a milieu that is found inside MVBs. In line with this, it was shown in SHSY5Y cells that synthetic A $\beta 1-42$ added to cell culture medium at $1 \mu \mathrm{M}$ was taken up and formed aggregates of $A \beta$ inside these cells, while only monomers could be found in the cell culture medium even after 5 days [45]. Overall, these results are consistent with the notion that aggregation of $A \beta 1-42$ is promoted inside acidic endocytic compartments. Friedrich et al. (2010) [46] demonstrated in a macrophage cell line, bundles of $A \beta 1-40$ fibrils in MVBs that penetrated the MVB membrane and leaked into the cytoplasm. We now present the first experimental evidence of $A \beta 42$ aggregates developing inside MVBs/late endocytic/lysosomal compartments of cultured neurons.

We also found evidence of loss of endolysosomal impermeability with $A \beta 1-42$ treatment of neurons, in line with reports in non-neuronal cells [47]. Further, we show that
$\mathrm{A} \beta$ fibrillar oligomers/fibrils are visible inside neurons in a vesicular pattern as early as $45 \mathrm{~min}$ after addition of $\mathrm{A} \beta 1$ 42 to the cell medium, that are not seen when only labelling the cell surface. Remarkably, at later time points intracellular aggregates are larger and extend into elongated structures that appear to penetrate the plasma membrane or are potentially even secreted or extruded into the extracellular space. Of note, the part of the elongated OC antibody positive structures that developed with time and no longer colabeled with the human $A \beta$ specific antibody, might represent (1) $A \beta$ where the $\mathrm{N}$-terminal antibody binding sites become inaccessible to the antibody, (2) endogenous mouse $A \beta$ aggregation and/or (3) incorporation of other amyloidogenic proteins. We demonstrate the ESCRT proteins VPS4A and Tsg101 in plaques of two different AD transgenic mouse models. Moreover, these ESCRT proteins strongly colocalized with a neuronal specific marker of the endo-lysosomal pathway, indicating the neuronal origin of the ESCRT proteins in plaques. Previously the lysosomal hydrolases cathepsin $\mathrm{D}$ and $\beta$-hexosaminidase $\mathrm{A}$ were shown to colocalize with $A \beta$ in a subgroup of diffuse plaques of $\mathrm{AD}$ and DS patients [48] consistent with an endolysosomal origin of aggregated $A \beta$. However, whether these lysosomal proteins were derived from glial cells or neurons was not determined in that study.

Expression of VPS4 mutants deficient in ATP hydrolysis, such as the dominant negative VPS4 E228Q used in this study, leads to enlarged vesicles defined as a class $\mathrm{E}$ phenotype, resulting from disruption of ESCRT-III recycling [49-51]. VPS4 acts after the membrane scission step to recycle ESCRT-III proteins back to monomers, so that they are available to start a second wave of ILV formation [52]. One might speculate that $A \beta$ disturbs this recycling leading to enlarged endocytic vesicles.

We show that inhibition of the late ESCRT machinery component VPS4A mimics AD pathogenesis by causing a marked increase in intracellular accumulation of $A \beta$ and a concomitant decrease in secreted $A \beta$, consistent with what was reported in cultures of $\mathrm{AD}$-transgenic compared to wt neurons [40]. Choy et al., 2012, reported that depletion of Hrs and Tsg101 in HEK293 cells stably expressing APP695 reduced $A \beta$ secretion [53] and Edgar et al. (2015) found reduced $A \beta 40$ secretion and increased intracellular $A \beta$ when depleting APP overexpressing N2a cells of Hrs or Tsg101 
[54], consistent with a role for the ESCRT machinery in preventing intracellular $A \beta$ accumulation. However, in contrast to reduced $A \beta$ secretion on depletion of early ESCRTs, Choy et al. found increased A 340 secretion upon VPS4A depletion with siRNA [53]. The difference with our demonstration of reduced $A \beta$ secretion upon expression of dnVPS4 might be explained by the different cell types and methods of altering VPS4A that were used.

We provide evidence that the reduced secretion of $A \beta$ with dnVPS4 was not due to reduced exosome secretion, since total exosome secretion was increased with dnVPS4A. Multiple mechanisms of ILV formation have been identified, but the relationship between different populations of ILVs and MVBs remains unclear. Both ESCRTdependent and ESCRT-independent mechanisms of MVB biogenesis exist in mammalian cells. A competitive relationship between ESCRT-dependent and -independent mechanisms of ILV formation within single MVBs has been suggested, with upregulation of CD63-dependent ILV formation from ESCRT depletion [33-35]. It was shown in HeLa-CIITA-OVA cells that depletion of VPS4B increased the secretion of CD63 positive exosomes [55], in line with our results of increased amounts of CD63 positive exosomes with dnVPS4A. It is interesting to note that in our EM data from APP/PS1 neurons and in wt neurons treated with $A \beta 1-42$, we saw both enlarged MVBs with many ILVs as well as enlarged MVBs with few ILVs. One can speculate that these might represent two different subsets of MVBs; it is possible that ESCRT-dependent ILV formation is disturbed by $\mathrm{A} \beta / \mathrm{APP}$, resulting in enlarged and empty MVBs, and potentially subsequent up-regulation of CD63 dependent ILVs formation resulting in MVBs filled with many ILVs. Others have reported that formation of ILVs destined for exosomal release was not ESCRT dependent, while ESCRTs were necessary for ILVs destined for degradation in the lysosome [56].

The intraneuronal pool of $A \beta$ can have a dual origin, namely the production of $\mathrm{A} \beta$ from APP inside neurons and uptake of $A \beta$ from the extracellular space that is secreted by other cells and/or the same neuron. Although we saw a net increase in intracellular $A \beta$ levels with the expression of dnVPS4A supporting impaired degradation of $A \beta$ and APP, we can not rule out that the production of $A \beta$ from APP inside neurons was unaffected. In the OC antibody positive dnVPS4A-transfected cells, the enlarged vesicles also colocalized with increased labelling of flotillin-1 (Fig. 4g), hence associating with cholesterol-enriched lipid microdomains. Interestingly, ATPase-defective mammalian VPS4 was reported to localize to aberrant late endosomes accumulating cholesterol, due to impaired cholesterol trafficking [50] and retention of cholesterol in late endosomal/lysosomal compartments was reported to be associated with alterations in APP processing [57].
Our data also demonstrate that defective MVBs, modelled by dnVPS4A, leads to increased tau phosphorylation at serine 396 (S396). This site is phosphorylated by GSK3 $\beta$; hence the increased tau phosphorylation could be due to impaired GSK3 $\beta$ sequestration into MVBs. Immunofluorescent labelling of GSK3 $\beta$ was increased with dnVPS4A (Additional file 10: Figure S9A), although total levels of GSK3 $\beta$ or GSK $3 \alpha / \beta$ phosphorylated at serine $21 / 9$ were not changed by Western blot. Hence, we cannot fully conclude that defective sequestration of GSK3 $\beta$ into MVBs is responsible for the increased levels of tau phosphorylation that we see with dnVPS4. However, consistent with our results, Tg APP-V7171 mice with the London mutation were found to have increased phosphorylation of tau at S396 and increased GSK3 $\beta$ activity, but no change in total levels of GSK3 $\beta$ and GSK3 $\beta$ phosphorylated at serine 9 [58].

We show that $A \beta$ aggregation can initiate inside nerve cells from vesicular accumulation of $\mathrm{A} \beta$. Aberrant endosomal trafficking has been linked genetically and biologically to a number of neurodegenerative diseases. Proteins involved in endocytosis are also prominent among genes linked to AD [11]. Interestingly, CD2AP, which is genetically linked to late onset $\mathrm{AD}$ and has been reported to affect MVB biogenesis and ILV formation [59], was recently reported to elevate levels of intracellular $A \beta$ in dendrites [60]. While the ESCRT-III protein CHMP2B was first genetically linked to FTD [23], copy number variation in CHMP2B has since been reported in a family with familial Alzheimer's disease [24] and genome-wide association studies for late onset AD identified an association with VPS4B [25]. Moreover, immunoreactivity for CHMP2B is increased in neurons of hippocampus in another characteristic neuropathology of AD, granulovacuolar degeneration (GVD) [61]. CHMP2B-positive GVDs were reported to colocalize to a greater extent with the late endosomal/lysosomal marker LAMP1 than to the lysosomal marker cathepsin $\mathrm{D}$ or to the autophagic markers LC3 and p62, suggesting a late endosomal origin of GVDs or that they accumulate at the nexus of autophagic and endocytic pathways [62]. It is interesting to note that we found CHMP2B immunoreactivity particularly in hippocampus and medial temporal lobe of 3-month-old Tg19959 mice before plaque pathology, the two areas that are the first to have GVD-affected neurons in AD [63].

\section{Conclusions}

Neuropathological studies have pointed to an early and aberrant accumulation and aggregation of $A \beta$ within neurons in $\mathrm{AD}$, in particular in dystrophic neurites. Cell biological studies that model this aggregation in neurons are valuable in delineating the molecular mechanisms of $A \beta$-related synaptic dysfunction. We propose a model where elevated 
levels of $A \beta 42$ cause enlarged and defective MVBs, possibly via effects on ESCRT-III components. Alternatively, MVB dysfunction, as modelled by the expression of dnVPS4A, can lead to accumulation of $A \beta$ in enlarged endocytic compartments. These results support a scenario where disturbances in the MVB pathway caused by $A \beta 42$, or vice versa, could turn into a vicious cycle where more $A \beta 42$ accumulates and oligomeric and fibrillar aggregates form. Our findings that ESCRT components colocalize with $A \beta 42$ in amyloid plaques in two different mouse models of AD support the scenario that aggregated A 442 in MVBs/late endocytic compartments, potentially together with ESCRTcomponents could serve as seeds for plaques.

\section{Additional files}

Additional file 1: Table S1. List of antibodies. (PDF 35 kb)

Additional file 2: Figure S1. (A) EM image of an enlarged MVB in wt neurons treated with $A \beta 1-42$. This image shows an example of an enlarged MVB with very few ILVs. (B) Confocal analysis of changes in size of LAMP1-positive structures in A 1-42 treated wt primary neurons with time. Scale bar $40 \mu \mathrm{m}$. (PDF 8949 kb)

Additional file 3: Figure S2. (A) Confocal analysis of wt primary neurons show that untreated (DMSO) cells have no OC labelling, while cells incubated with $A \beta 1-40$ for $48 \mathrm{~h}$ have low levels of OC labelling. However, cells incubated with AB1-42 display very strong OC labelling. (PDF 4679 kb)

Additional file 4: Figure S3. (A) The early relatively weak $O C$ labelling at 45 min of A 1-42 treatment colocalizes with LAMP1 labelling in the neurites, but not with the large LAMP1-positive structures in the cell soma. Confocal analysis of wt primary neurons treated with AB1-42 for 45 min. Scale $20 \mu \mathrm{m}$. (B) After 48 h of A $1-42$ treatment, OC labelling is stronger and colocalizes partly with LAMP1-positive structures that appear enlarged and irregular in their shape. Elongated OC-positive structures extend out from such punctate LAMP1 labelling in the neuronal processes. Scale $20 \mu \mathrm{m}$. (C) At high magnification, antibody OC labelling can be seen colocalizing with the late endocytic marker Rab7 in neuronal processes of wt neurons treated for $24 \mathrm{~h}$ with AB1-42. Scale bar $5 \mu \mathrm{m}$. (PDF 269 kb)

Additional file 5: Figure S4. ESCRT proteins in primary neurons and plaques. (A-B) In young 3-month-old Tg19959 mice, CHMP2B immunolabelling is increased in areas of hippocampus (a) and entorhinal cortex (b) that also have increased labelling of APP/A $(6 E 10)$. Scale bar $40 \mu \mathrm{m}, n=4$. (C) Western blot analysis of APP/PS1 compared to wt primary neurons at 12 DIV lysed in $6 \%$ SDS shows that protein levels of CHMP2B and VPS4 are not significantly changed, although there is a trend for increased levels of CHMP2B in APP/PS1 neurons, $n>6$. Protein levels are expressed as percentage of control and are corrected against actin. (D) VPS4 colocalizes with A 42 in a vesicular pattern in 19-month-old wt mice (upper panel), $n=3$. In 19-month-old APP/PS1 mice VPS4 accumulates in and around amyloid plaques (lower panel, white arrows). Scale bar $40 \mu \mathrm{m}, n=4$. (E) Decreased labelling of CHMP2B in plaques (white arrows) in 19-month-old APP/PS1 mice. Some colocalization of CHMP2B is seen in AB/APP (6E10) positive cells (grey arrows). Scale bar $40 \mu \mathrm{m}, n=3$. (F) Labelling of early ESCRT-0 component Hrs is decreased in amyloid plaques compared to surrounding brain parenchyma. Scale bar $40 \mu \mathrm{m}, n=2$. (PDF $13619 \mathrm{~kb}$ )

Additional file 6: Figure S5. A $\beta 1-42$ increases the diameter of LAMP-1 positive vesicles in N2a cells. Confocal images of exogenously added monomeric $A \beta 1-42$ incubated for different time points, ranging from $15 \mathrm{~min}$ to $48 \mathrm{~h}$, in N2a cells. 3D-rendering with Imaris from confocal z-stack. Colocalization of OC labelling and LAMP1 labelling can be seen from 45 min of A $\beta$ treatment. The last image is from a single focal plane showing $O C$ labelling inside an enlarged LAMP1-positive structure as well as OC labelling that appears to localize at the cell surface. Scale bar $10 \mu \mathrm{m}$. (PDF $375 \mathrm{~kb}$ )

Additional file 7: Figure S6. DnVPS4A increases secretion but does not change levels of intracellular a-syn. (A) Western blot analysis of a-syn N2a cells transfected with dnVPS4A shows increased levels of extracellular asynuclein without altering the total pool of intracellular a-synuclein. (B) Quantification of A. Values are normalized against actin and expressed as percentage of control, $n=3 ;{ }^{*} p<0.05,{ }^{* *} p<0.01$. (C) Overexposed WB membrane for secreted a-synuclein (same as above) with increased intensity to better visualize the bands. (PDF $1607 \mathrm{~kb}$ )

Additional file 8: Figure S7. (A) Western blot analysis of APP and A in Swe N2a cells treated with $40 \mu \mathrm{g} / \mathrm{ml}$ cycloheximide $(\mathrm{CHX})$ at different times in hours (h) before harvest. Cell culture media was replaced with fresh media $24 \mathrm{~h}$ before harvest. For quantification, values are normalized against actin and expressed as percentage of control, $n=3$; ${ }^{*} p<0.05$, ${ }^{* *} p<0.01,{ }^{* * *} p<0.001,{ }^{* * * *} p<0.0001$ (ANOVA with Dunnett's multiple comparisons test, compared to ctr). (B) Confocal images of $6 \mathrm{E} 10$ and Golgi marker GM130 in Swe N2a cells treated with $40 \mu \mathrm{g} / \mathrm{ml}$ CHX for the depicted times. (PDF $2263 \mathrm{~kb}$ )

Additional file 9: Figure S8. (A) Western blot analysis of APP and AB in Swe N2a cells treated with 5 nM bafilomycin A1 (BafA1) at different time points (h) before harvest. Cell culture media was replaced with fresh media 24 h before harvest. (B) Quantification of A. Values are normalized against actin and expressed as percentage of control, $n=3$; ${ }^{*} p<0.05$, ${ }^{* *} p<0.01,{ }^{* * *} p<0.001,{ }^{* * *} p<0.0001$ (ANOVA with Dunnett's multiple comparisons test, compared to ctr). (C) Confocal images of $6 \mathrm{E} 10$ and LAMP1 labelling in Swe N2a cells treated with $5 \mathrm{nM}$ bafilomycin A1 for the depicted times. At $24 \mathrm{~h}$ there is a build up of both $6 \mathrm{E} 10$ labelling and punctate LAMP1-positive structures. (D) Western blot analysis of APP and $\mathrm{A} \beta$ in Swe N2a cells treated with $5 \mathrm{nM}$ bafilomycin A1 (BafA1) $24 \mathrm{~h}$ before harvest and $40 \mu \mathrm{g} / \mathrm{ml}$ cycloheximide $(\mathrm{CHX})$ at different time points (h) before harvest. Cell culture media was replaced with fresh media $24 \mathrm{~h}$ before harvest, before the addition of Baf A1. (PDF $1310 \mathrm{~kb}$ )

Additional file 10: Figure S9. (A) 3D images show increased GSK3 $\beta$ labelling in dnVPS4-expressing N2a Swe compared to cells transfected with control plasmid. Rab7 labelling is also increased in dnVPS4 expressing cells. Scale bar $15 \mu \mathrm{m}$. (B) Western blot analysis of cell lysates of Swe N2a cells transfected with dnVPS4A showing no changes in total GSK3 $\beta$ or phosphorylated GSK3a/ $\beta$ (serine 21/9). (PDF 5570 kb)

\section{Abbreviations}

AD: Alzheimer's disease; APP: Amyloid precursor protein; APP/PS1: B6.Cg-Tg (APPswe,PSEN1dE9)85Dbo/Mmjax mice; BACE1: Beta-secretase 1; BafA1: Bafilomycin A1; BSA: Bovine serum albumin; DIV: Days in vitro; dnVPS4A: Dominant negative VPS4A; EM: Electron microscopy; ESCRT: Endosomal sorting complexes required for transport; FTD: Frontotemporal dementia; ILV: Intraluminal vesicle; MVB: Multivesicular bodies; NFTs: Neurofibrillary tangles; NGS: Normal goat serum; PBS: Phosphate buffered saline; PBST: PBS containing 0.1\% Tween-20; PFA: Paraformaldehyde; PS1: Presenilin 1; RT: Room temperature; SDS: Sodium dodecyl sulfate; TCA: Trichloroacetic acid; tg: AD transgenic; wtVPS4A: Wild type VPS4A

\section{Acknowledgements}

We thank Drs. Gopal Thinakaran and Sangram Sisodia at the University of Chicago for sharing their stably transfected human APP N2a cells. We also thank Bodil Israelsson at Lund University for technical support.

\section{Funding}

This study was supported by MultiPark, Parkinsonsfonden and the Swedish Research Council.

\section{Availability of data and materials}

The datasets used and/or analysed during the current study are available from the corresponding author on reasonable request.

\section{Authors' contributions}

KW and GKG conceived the study; KW performed and analysed all experiments except for the EM imaging, which was performed and analysed by JRE and CEF; TH and NT supplied the p3xFLAG-CMV-10-hVPS4A-wt and p3xFLAG-CMV-10-hVPS4A-dn plasmids; KW wrote the paper, with input and editing provided by GKG, JRE and CEF. All authors read and approved the final manuscript. 


\section{Ethics approval}

All animal experiments were approved by the Animal Ethical Committee of Malmö and Lund, reference number M40-14.

\section{Consent for publication}

Not applicable.

\section{Competing interests}

The authors declare that they have no competing interests.

\section{Publisher's Note}

Springer Nature remains neutral with regard to jurisdictional claims in published maps and institutional affiliations.

\begin{abstract}
Author details
'Department of Experimental Medical Science, Lund University, 22184 Lund, Sweden. ${ }^{2}$ Cambridge Institute for Medical Research, University of Cambridge, Cambridge CB2 OXY, UK. ${ }^{3} \mathrm{UCL}$ Institute of Ophthalmology, London EC1V 9EL, UK. ${ }^{4}$ Division of Neurology, Department of Neuroscience and Sensory Organs, Tohoku University Graduate School of Medicine, Sendai 980-8574, Japan. ${ }^{5}$ Division of Cancer Biology and Therapeutics, Miyagi Cancer Center Research Institute, Natori 981-1293, Japan.
\end{abstract}

\section{Received: 6 February 2017 Accepted: 15 August 2017}

Published online: 23 August 2017

\section{References}

1. Cataldo AM, Petanceska S, Terio NB, Peterhoff CM, Durham R, Mercken M, Mehta PD, Buxbaum J, Haroutunian V, Nixon RA. Abeta localization in abnormal endosomes: association with earliest Abeta elevations in $A D$ and down syndrome. Neurobiol Aging. 2004;25:1263-72.

2. D'Andrea MR, Nagele RG, Wang HY, Peterson PA, Lee DHS. Evidence that neurones accumulating amyloid can undergo lysis to form amyloid plaques in Alzheimer's disease. Histopathology. 2001;38:120-34.

3. Gouras GK, Tsai J, Naslund J, Vincent B, Edgar M, Checler F, Greenfield JP, Haroutunian V, Buxbaum JD, Xu H, Greengard P, Relkin NR. Intraneuronal Ab42 accumulation in human brain. Am J Pathol. 2000;156:15-20.

4. Oakley H, Cole SL, Logan S, Maus E, Shao P, Craft J, Guillozet-Bongaarts A, Ohno M, Disterhoft J, Van Eldik L, Berry R, Vassar R. Intraneuronal betaamyloid aggregates, neurodegeneration, and neuron loss in transgenic mice with five familial Alzheimer's disease mutations: potential factors in amyloid plaque formation. J Neurosci. 2006;26:10129-40.

5. Takahashi RH, Milner TA, Li F, Nam EE, Edgar MA, Yamaguchi H, Beal MF, Xu $\mathrm{H}$, Greengard P, Gouras GK. Intraneuronal Alzheimer Abeta42 accumulates in multivesicular bodies and is associated with synaptic pathology. Am J Pathol. 2002;161:1869-79.

6. Wirths O, Multhaup G, Czech C, Blanchard V, Moussaoui S, Tremp G, Pradier $L$, Beyreuther K, Bayer TA. Intraneuronal Abeta accumulation precedes plaque formation in beta-amyloid precursor protein and presenilin-1 double-transgenic mice. Neurosci Lett. 2001;306:116-20.

7. Billings LM, Oddo S, Green KN, McGaugh JL, LaFerla FM. Intraneuronal Abeta causes the onset of early Alzheimer's disease-related cognitive deficits in transgenic mice. Neuron. 2005;45:675-88.

8. Chapman PF, White GL, Jones MW, Cooper-Blacketer D, Marshall VJ, Irizarry M, Younkin L, Good MA, Bliss TV, Hyman BT, Younkin SG, Hsiao KK. Impaired synaptic plasticity and learning in aged amyloid precursor protein transgenic mice. Nat Neurosci. 1999;2:271-6.

9. Takahashi RH, Almeida CG, Kearney PF, Yu F, Lin MT, Milner TA, Gouras GK. Oligomerization of Alzheimer's beta-amyloid within processes and synapses of cultured neurons and brain. J Neurosci. 2004;24:3592-9.

10. Gouras GK, Tampellini D, Takahashi RH, Capetillo-Zarate E. Intraneuronal beta-amyloid accumulation and synapse pathology in Alzheimer's disease. Acta Neuropathol. 2010;119:523-41.

11. Peric A, Annaert W. Early etiology of Alzheimer's disease: tipping the balance toward autophagy or endosomal dysfunction? Acta Neuropathol. 2015;129:363-81.

12. Cataldo AM, Peterhoff CM, Troncoso JC, Gomez-Isla T, Hyman BT, Nixon RA. Endocytic pathway abnormalities precede amyloid beta deposition in sporadic Alzheimer's disease and down syndrome: differential effects of APOE genotype and presenilin mutations. Am J Pathol. 2000;157:277-86.
13. Cataldo AM, Mathews PM, Boiteau AB, Hassinger LC, Peterhoff CM, Jiang $Y$, Mullaney K, Neve RL, Gruenberg J, Nixon RA. Down syndrome fibroblast model of Alzheimer-related endosome pathology: accelerated endocytosis promotes late endocytic defects. Am J Pathol. 2008;173:370-84.

14. Nixon RA, Wegiel J, Kumar A, Yu WH, Peterhoff C, Cataldo A, Cuervo AM. Extensive involvement of autophagy in Alzheimer disease: an immunoelectron microscopy study. J Neuropathol Exp Neurol. 2005;64:113-22.

15. Small SA, Gandy S. Sorting through the cell biology of Alzheimer's disease: intracellular pathways to pathogenesis. Neuron. 2006;52:15-31.

16. De Strooper B, Vassar R, Golde T. The secretases: enzymes with therapeutic potential in Alzheimer disease. Nat Rev Neurol. 2010;6:99-107.

17. Rajendran L, Annaert W. Membrane trafficking pathways in Alzheimer's disease. Traffic. 2012;13:759-70.

18. Sannerud R, Declerck I, Peric A, Raemaekers T, Menendez G, Zhou L, Veerle B, Coen K, Munck S, De Strooper B, Schiavo G, Annaert W. ADP ribosylation factor 6 (ARF6) controls amyloid precursor protein (APP) processing by mediating the endosomal sorting of BACE1. Proc Natl Acad Sci U S A. 2011; 108:E559-68.

19. Sannerud R, Esselens C, Ejsmont P, Mattera R, Rochin L, Tharkeshwar AK, De Baets G, De Wever V, Habets R, Baert V, Vermeire W, Michiels C, Groot AJ, Wouters R, Dillen K, Vints K, Baatsen P, Munck S, Derua R, Waelkens E, Basi GS, Mercken M, Vooijs M, Bollen M, Schymkowitz J, Rousseau F, Bonifacino JS, Van Niel G, De Strooper B, Annaert W. Restricted location of PSEN2/YSecretase determines substrate specificity and generates an intracellular $A \beta$ pool. Cell. 2016;166:193-208.

20. Langui D, Girardot N, El Hachimi KH, Allinquant B, Blanchard V, Pradier L, Duyckaerts C. Subcellular topography of neuronal Abeta peptide in APPxPS1 transgenic mice. Am J Pathol. 2004;165:1465-77.

21. Almeida C, Takahashi H, Gouras GK. Beta-amyloid accumulation impairs multivesicular body sorting by inhibiting the ubiquitin-proteasome system. J Neurosci. 2006;26:4277-88.

22. Babst M, Katzmann DJ, Estepa-Sabal EJ, Meerloo T, Emr SD. Escrt-III: an endosome-associated heterooligomeric protein complex required for mvb sorting. Dev Cell. 2002;3:271-82.

23. Skibinski G, Parkinson NJ, Brown JM, Chakrabarti L, Lloyd SL, Hummerich H, Nielsen JE, Hodges JR, Spillantini MG, Thusgaard T, Brandner S, Brun A, Rossor MN, Gade A, Johannsen P, Sørensen SA, Gydesen S, Fisher EM, Collinge J. Mutations in the endosomal ESCRTIII-complex subunit CHMP2B in frontotemporal dementia. Nat Genet. 2005;37:806-8.

24. Hooli BV, Kovacs-Vajna ZM, Mullin K, Blumenthal MA, Mattheisen M, Zhang C, Lange C, Mohapatra G, Bertram L, Tanzi RE. Rare autosomal copy number variations in early-onset familial Alzheimer's disease. Mol Psychiatry. 2014;19:676-81.

25. Jones L, Holmans PA, Hamshere ML, Harold D, Moskvina V, Ivanov D, Pocklington A, Abraham R, Hollingworth P, Sims R, Gerrish A, Pahwa JS, Jones N, Stretton A, Morgan AR, Lovestone S, Powell J, Proitsi P, Lupton MK, Brayne C, Rubinsztein DC, Gill M, Lawlor B, Lynch A, Morgan K, Brown KS, Passmore PA, Craig D, McGuinness B, Todd S, Holmes C, Mann D, Smith AD, Love S, Kehoe PG, Mead S, Fox N, Rossor M, Collinge J, Maier W, Jessen F, Schürmann B, Heun R, Kölsch $H$, van den Bussche $H$, Heuser I, Peters $O$, Kornhuber J, Wiltfang J, Dichgans M, Frölich L, Hampel H, Hüll M, Rujescu D, Goate AM, Kauwe JS, Cruchaga C, Nowotny P, Morris JC, Mayo K, Livingston G, Bass NJ, Gurling H, McQuillin A, Gwilliam R, Deloukas P, Al-Chalabi A, Shaw CE, Singleton AB, Guerreiro R, Mühleisen TW, Nöthen MM, Moebus S, Jöckel KH, Klopp N, Wichmann HE, Rüther E, Carrasquillo MM, Pankratz VS, Younkin SG, Hardy J, O'Donovan MC, Owen MJ, Williams J. Genetic evidence implicates the immune system and cholesterol metabolism in the aetiology of Alzheimer's disease. PLoS One. 2010;5:e13950.

26. Thinakaran G, Teplow DB, Siman R, Greenberg B, Sisodia SS. Metabolism of the "Swedish" amyloid precursor protein variant in neuro2a (N2a) cells. Evidence that cleavage at the "beta-secretase" site occurs in the golgi apparatus. J Biol Chem. 1996;271:9390-7.

27. Slot JW, Geuze HJ. A new method of preparing gold probes for multiplelabeling cytochemistry. Eur J Cell Biol. 1985;38:87-93.

28. Hasegawa T, Konno M, Baba T, Sugeno N, Kikuchi A, Kobayashi M, Miura E, Tanaka N, Tamai K, Furukawa K, Arai H, Mori F, Wakabayashi K, Aoki M, Itoyama Y, Takeda A. The AAA-ATPase VPS4 regulates extracellular secretion and lysosomal targeting of a-synuclein. PLoS One. 2011;6:e29460.

29. Buxbaum JD, Gandy SE, Cicchetti P, Ehrlich ME, Czernik AJ, Fracasso RP, Ramabhadran TV, Unterbeck AJ, Greengard P. Processing of Alzheimer beta/ A4 amyloid precursor protein: modulation by agents that regulate protein phosphorylation. Proc Natl Acad Sci U S A. 1990;87:6003-6. 
30. Théry C, Amigorena S, Raposo G, Clayton A. Isolation and characterization of exosomes from cell culture supernatants and biological fluids. Curr Protoc Cell Biol. 2006;30(3.22):3.22.1-3.22.29.

31. Kayed R, Head E, Sarsoza F, Saing T, Cotman CW, Necula M, Margol L, Wu J, Breydo L, Thompson JL, Rasool S, Gurlo T, Butler P, Glabe CG. Fibril specific, conformation dependent antibodies recognize a generic epitope common to amyloid fibrils and fibrillar oligomers that is absent in prefibrillar oligomers. Mol Neurodegener. 2007;2:18.

32. Katoh Y, Ritter B, Gaffry T, Blondeau F, Höning S, McPherson PS. The clavesin family, neuron-specific lipid- and clathrin-binding sec14 proteins regulating lysosomal morphology. J Biol Chem. 2009;284:27646-54.

33. Stuffers S, Sem Wegner C, Stenmark H, Brech A. Multivesicular endosome biogenesis in the absence of ESCRTs. Traffic. 2009;10:925-37.

34. van Niel G, Charrin S, Simoes S, Romao M, Rochin L, Saftig P, Marks MS, Rubinstein E, Raposo G. The tetraspanin CD63 regulates ESCRT-independent and -dependent endosomal sorting during melanogenesis. Dev Cell. 2011;21:708-21.

35. Edgar JR, Eden ER, Futter CE. Hrs- and CD63-dependent competing mechanisms make different sized endosomal intraluminal vesicles. Traffic. 2014;15:197-211

36. Taelman VF, Dobrowolski R, Plouhinec JL, Fuentealba LC, Vorwald PP, Gumper I, Sabatini DD, De Robertis EM. Wnt signaling requires sequestration of glycogen synthase kinase 3 inside multivesicular endosomes. Cell. 2010;143:1136-48.

37. Kimura T, Whitcomb DJ, Jo J, Regan P, Piers T, Heo S, Brown C, Hashikawa T, Murayama M, Seok H, Sotiropoulos I, Kim E, Collingridge GL, Takashima A, Cho K. Microtubule-associated protein tau is essential for long-term depression in the hippocampus. Philos Trans R Soc Lond Ser B Biol Sci. 2013;369:20130144.

38. Hooper C, Killick R, Lovestone S. The GSK3 hypothesis of Alzheimer's disease. J Neurochem. 2008;104:1433-9.

39. Dunning CJ, McGauran G, Willén K, Gouras GK, O'Connell DJ, Linse S. Direct high affinity interaction between AB42 and GSK3a stimulates hyperphosphorylation of tau. A new molecular link in Alzheimer's disease? ACS Chem Neurosci. 2016;7:161-70

40. Tampellini D, Rahman N, Lin MT, Capetillo-Zarate E, Gouras GK. Impaired beta-amyloid secretion in Alzheimer's disease pathogenesis. J Neurosci. 2011;31:15384-90.

41. Tampellini D, Capetillo-Zarate E, Dumont M, Huang Z, Yu F, Lin MT, Gouras GK. Effects of synaptic modulation on beta-amyloid, synaptophysin, and memory performance in Alzheimer's disease transgenic mice. J Neurosci. 2010;30:14299-304.

42. Kim S, Sato Y, Mohan PS, Peterhoff C, Pensalfini A, Rigoglioso A, Jiang Y, Nixon RA. Evidence that the rab5 effector APPL1 mediates APP- $\beta C T F-$ induced dysfunction of endosomes in down syndrome and Alzheimers disease. Mol Psychiatry. 2016;21:707-16.

43. Lauritzen I, Pardossi-Piquard R, Bourgeois A, Pagnotta S, Biferi MG, Barkats M, Lacor P, Klein W, Bauer C, Checler F. Intraneuronal aggregation of the $\beta$-CTF fragment of APP (C99) induces A $\beta$-independent lysosomal-autophagic pathology. Acta Neuropathol. 2016;132:257-76.

44. Burdick D, Soreghan B, Kwon M, Kosmoski J, Knauer M, Henschen A, Yates J, Cotman C, Glabe C. Assembly and aggregation properties of synthetic Alzheimer's A4/beta amyloid peptide analogs. J Biol Chem. 1992;267:546-54.

45. Hu X, Crick SL, Bu G, Frieden C, Pappu RV, Lee JM. Amyloid seeds formed by cellular uptake, concentration, and aggregation of the amyloid-beta peptide. Proc Natl Acad Sci U S A. 2009;1(106):20324-9.

46. Friedrich RP, Tepper K, Rönicke R, Soom M, Westermann M, Reymann K, Kaether C, Fändrich M. Mechanism of amyloid plaque formation suggests an intracellular basis of A $\beta$ pathogenicity. Proc Natl Acad Sci U S A. 2010;107:1942-7.

47. Yang AJ, Chandswangbhuvana D, Margol L, Glabe CG. Loss of endosomal/ lysosomal membrane impermeability is an early event in amyloid Abeta1-42 pathogenesis. J Neurosci Res. 1998;52:691-8.

48. Cataldo AM, Barnett JL, Mann DM, Nixon RA. Colocalization of lysosomal hydrolase and beta-amyloid in diffuse plaques of the cerebellum and striatum in Alzheimer's disease and Down's syndrome. J Neuropathol Exp Neurol. 1996;55:704-15.

49. Babst M, Wendland B, Estepa EJ, Emr SD. The Vps4p AAA ATPase regulates membrane association of a Vps protein complex required for normal endosome function. EMBO J. 1998;11:2982-93.

50. Bishop N, Woodman P. ATPase-defective mammalian VPS4 localizes to aberrant endosomes and impairs cholesterol trafficking. Mol Biol Cell. 2000; 11:227-39.
51. Dores MR, Chen B, Lin H, Soh UJ, Paing MM, Montagne WA, Meerloo T, Trejo J. ALIX binds a YPX(3)L motif of the GPCR PAR1 and mediates ubiquitin-independent ESCRT-III/MVB sorting. J Cell Biol. 2012;197:407-19.

52. Wollert T, Wunder C, Lippincott-Schwartz J, Hurley JH. Membrane scission by the ESCRT-III complex. Nature. 2009;458:172-7.

53. Choy RW, Cheng Z, Schekman R. Amyloid precursor protein (APP) traffics from the cell surface via endosomes for amyloid $\beta$ (A $\beta$ ) production in the trans-Golgi network. Proc Natl Acad Sci U S A. 2012;109:E2077-82.

54. Edgar JR, Willén K, Gouras GK, Futter CE. ESCRTs regulate amyloid precursor protein sorting in multivesicular bodies and intracellular amyloid- $\beta$ accumulation. J Cell Sci. 2015;128:2520-8.

55. Colombo M, Moita C, van Niel G, Kowal J, Vigneron J, Benaroch P, Manel N, Moita LF, Théry C, Raposo G. Analysis of ESCRT functions in exosome biogenesis, composition and secretion highlights the heterogeneity of extracellular vesicles. J Cell Sci. 2013;126:5553-65.

56. Trajkovic K, Hsu C, Chiantia S, Rajendran L, Wenzel D, Wieland F, Schwille P, Brügger $B$, Simons M. Ceramide triggers budding of exosome vesicles into multivesicular endosomes. Science. 2008;319:1244-7.

57. Runz H, Rietdorf J, Tomic I, de Bernard M, Beyreuther K, Pepperkok R, Hartmann T. Inhibition of intracellular cholesterol transport alters presenilin localization and amyloid precursor protein processing in neuronal cells. J Neurosci. 2002;22:679-89.

58. Terwel D, Muyllaert D, Dewachter I, Borghgraef $P$, Croes S, Devijver H, Van Leuven F. Amyloid activates GSK-3beta to aggravate neuronal tauopathy in bigenic mice. Am J Pathol. 2008;172:786-98.

59. Kim JM, Wu H, Green G, Winkler CA, Kopp JB, Miner JH, Unanue ER, Shaw AS. CD2-associated protein haploinsufficiency is linked to glomerular disease susceptibility. Science. 2003;300:1298-300.

60. Ubelmann F, Burrinha T, Salavessa L, Gomes R, Ferreira C, Moreno N, Guimas AC. Bin1 and CD2AP polarise the endocytic generation of beta-amyloid. EMBO Rep. 2017;18:102-22.

61. Yamazaki Y, Takahashi T, Hiji M, Kurashige T, Izumi Y, Yamawaki T, Matsumoto M. Immunopositivity for ESCRT-III subunit CHMP2B in granulovacuolar degeneration of neurons in the Alzheimer's disease hippocampus. Neurosci Lett. 2010;477:86-90.

62. Funk KE, Mrak RE, Kuret J. Granulovacuolar degeneration (GVD) bodies of Alzheimer's disease (AD) resemble late-stage autophagic organelles. Neuropathol Appl Neurobiol. 2011;37:295-306.

63. Thal DR, Del Tredici K, Ludolph AC, Hoozemans JJ, Rozemuller AJ, Braak H, Knippschild U. Stages of granulovacuolar degeneration: their relation to Alzheimer's disease and chronic stress response. Acta Neuropathol. 2011; 122:577-89.

\section{Submit your next manuscript to BioMed Central and we will help you at every step:}

- We accept pre-submission inquiries

- Our selector tool helps you to find the most relevant journal

- We provide round the clock customer support

- Convenient online submission

- Thorough peer review

- Inclusion in PubMed and all major indexing services

- Maximum visibility for your research

Submit your manuscript at www.biomedcentral.com/submit
Biomed Central 